\title{
Historiografía y Relaciones Internacionales en América Latina: Entre la Rebeldía Autonomista y la Sumisión Occidentalista
}

\author{
Yetzy Urimar Villarroel Peña*
}

\begin{abstract}
ReSUMen
Durante una buena parte del tiempo, el conocimiento práctico de las Relaciones Internacionales estuvo ligado casi exclusivamente a los registros generados por la Historia, de tal manera que ésta ha cumplido una función importante tanto en el desarrollo teórico como práctico de la disciplina. Por ello, es muy frecuente entre los internacionalistas la alusión al historiador Tucídides, a las crónicas de reyes, a las justificaciones del estado y sus comportamientos basados en análisis históricos del mundo occidental. En esta investigación se intentará analizar la utilización de la historia en América Latina, en la reafirmación de la identidad de sus estados y en el abordaje de su inserción en el sistema internacional. En tal sentido se buscará: 1) Determinar si existe una historiografía latinoamericana y cuál ha sido su influencia en las relaciones internacionales de la región; 2) Analizar el papel de la historia en la configuración de las identidades de la región y su impacto en el comportamiento internacional, mediante imaginarios sociales y conciencia colectiva; 3) Analizar cómo desde la perspectiva histórica se pueden comprender las políticas exteriores de los estados latinoamericanos. Para ello se recurrirá a la metodología cualitativa, multidisciplinaria, enfatizando en el método histórico, revisando y analizando fuentes primarias y secundarias que permitan una aproximación al desarrollo de los objetivos planteados y tratando muy bien de delimitar lo mejor posible el objeto de estudio, evitando caer en generalizaciones inconvenientes y respetando las especificidades cuando sea necesario.
\end{abstract}

\section{Palabras clave}

América Latina; historiografía; método histórico; autonomía; occidente.

\section{TITLE}

Historiography and International Relations in Latin America: Between the Autonomist Rebellion and the Westernist Submission

\begin{abstract}
For a long time, the working knowledge about international relations was associated almost exclusively to the records generated by History, in consequence it has played an important role in both the theoretical and practical development of international relations. For this reason, it is very common among internationalists to mention historian Tucídides, the chronicles of kings, the raison d' être of the State and its behavior based on historical analyzes of the Western world. In this research we will seek to analyze the use of history, in Latin America, in the reaffirmation of the identity of its States and in dealing with insertion in the international system, in this respect we will try to 1 ) Determine the existence of Latin American historiography and what has been its influence in the international relations of the region, 2) Analyze the role of History in the shaping of identities in the region and its impact on international behavior, through popular and collective consciousness, 3) Analyze the Foreign Policies of Latin American States from a historical perspective and how can be understood. For this purpose, we will use the qualitative, multidisciplinary methodology, emphasizing the historical method by reviewing and analyzing primary and secondary sources that allow an approximation to the development of the objectives and trying to define the scope of study as well as possible, avoiding inconvenient generalizations and respecting the particularities when necessary.
\end{abstract}

\section{KEYWORDS}

Latin America; historiography; historical method; autonomy; west.
*Yetzy Urimar VILLARROEL PEÑA, Investigadora $y$ Profesora Asociada, adscrita al Departamento de Ciencias Sociales de la Universidad Simón Bolívar de Venezuela. Licenciada en Estudios Internacionales, con Maestría y Doctorado en Ciencia Política.

\section{Recibido:}

16-10-2017

Aceptado:

29-01-2018

DOI:

http://dx.doi.org/ 10.15366/relacionesinternacionales2018.37.006 


\section{ntroducción}

Durante una buena parte del tiempo, el conocimiento práctico de las Relaciones Internacionales estuvo ligado casi exclusivamente a los registros generados por la Historia, de tal manera que ésta ha cumplido una función importante tanto en el desarrollo teórico como práctico de las relaciones internacionales. Por ello, es muy frecuente entre los internacionalistas la alusión al historiador Tucídides, a las crónicas de reyes, a las justificaciones del estado y sus comportamientos basados en análisis históricos del mundo occidental.

Para esta investigación interesa hacer un recorrido por la historiografía latinoamericana de las relaciones internacionales, revisando sus especificidades, si las hay, su nacimiento, sus principales exponentes, las metodologías utilizadas, las perspectivas desde las cuales se han escrito, en síntesis, revisar cómo se ha desarrollado el proceso de creación y articulación de las ideas que han predominado en cada etapa de dicho proceso. No obstante, antes de realizar la revisión de los aspectos más importantes de su elaboración, es menester delimitar algunos conceptos que servirán de base a la argumentación.

El primer concepto que convoca, está relacionado con el objeto de estudio: ¿existe eso llamado América Latina? Y si existe, ¿qué es? Lo primero que viene a la mente es una realidad geográfica, no obstante, esa realidad geográfica en sí misma constituye un problema desde el punto de vista histórico, en el sentido que la superficie geográfica es anterior a 1492, y la denominación de la realidad experimentada en esa geografía que implica, es relativamente reciente.

El nombre de América aparece cuando los europeos que se toparon con este territorio se dieron cuenta que no era las Indias, ni el paraíso terrenal del que hablaba la Biblia, sino que se trataba de tierras pertenecientes a un continente desconocido por ellos, al cual se le comenzó a llamar América a partir de 1507 en honor a Américo Vespuccio. En tal sentido "no corresponde tanto a una realidad geográfica y telúrica, sino a una realidad cultural que se inicia sólo después del desembarco de Colón"1 para "designar aquello de lo cual la única información que se tiene es no tener información"².

Una cosa era lo que los europeos conquistadores y colonizadores pensaban sobre el lugar conquistado y colonizado, otra lo que sus habitantes originarios tenían como representación del lugar, y otra la que los habitantes del continente europeo entendían de conformidad con los relatos que llegaban desde las lejanas tierras. Tres paradigmas distintos y seguramente heterogéneos a lo interno de cada uno, que en el transcurso del tiempo comenzaron a dar forma a uno nuevo compartido por todos, o por lo menos por una gran mayoría, en la medida en que el nuevo continente se fue incorporando a la cultura occidental mediante la imposición, la dominación y la asimilación.

Paralelamente, al incorporarse los esclavos traídos de África, la resistencia indígena y los grupos mestizos que se fueron originando del cruce de todos los grupos humanos que

1 NEIRA, Hernán, "Latinoamérica" en SALAS ASTRIAN, Ricardo (Coord). Pensamiento Político Latinoamericano. Conceptos Fundamentales. Ediciones de la Universidad Católica Silva Henríquez, Santiago de Chile, 2005, p. 585.

2 Ibídem, p. 586. 
hacían vida en estos territorios, se conformó otro paradigma interpretativo de la geografía y de los acontecimientos que se sucedían en oposición al pensamiento europeo. De allí la constante e histórica tensión entre la búsqueda de una identidad propia y la necesidad de identificarse como parte de la cultura occidental, resaltando ciertas particularidades distintivas.

Hasta hace poco no se conocía el nombre con el que los pueblos originarios designaban al continente, no obstante, el movimiento indígena ha revelado que durante más de cinco siglos los Kunas de Panamá han resguardado el nombre del continente, y que el mismo corresponde al vocablo indígena Abya Yala que significa tierra madura de eterna juventud. De igual manera, los pueblos originarios han resguardado su propia filosofía de vida, conceptos e ideas, ${ }^{3}$ con lo que se evidencia que el continente en sí no estuvo desprovisto de su propia cosmovisión y mucho menos carente de identidad cultural, lo cual no quiere decir que haya sido uniforme, homogéneo o unívoca.

Sin embargo, siempre se dio por hecho que no existía un nombre aborigen del continente, que no existía una identidad distintiva y mucho menos una civilización, en su lugar, el nombre de América se impuso, así como las leyes, el idioma, la religión, las instituciones, el ordenamiento territorial y la autoridad gubernamental desde Europa, desestimando y negando las culturas preexistentes por considerarlas poco desarrolladas, inferiores o bárbaras, anteponiéndolas a la idea europea de civilización, otro elemento que ha sido eje transversal de las historia regional, es decir, lo bárbaro versus la civilización.

A partir de mediados del siglo XIX comienza a gestarse otra denominación, aparece la idea de América Latina, nuevamente nace producto de la iniciativa europea, esta vez desde la Francia de Napoleón III. Aparece por primera vez en 1836 bajo la pluma de Michael Chavalier ${ }^{4}$, como un concepto étnico geográfico que intentaba distinguir los territorios colonizados por anglosajones de los colonizados por países europeos de lengua latina:

"Francia, heredera de las naciones católicas europeas, lleva a América y al mundo entero la antorcha de las razas latinas, es decir, francesa, italiana, española y portuguesa [...] Sin embargo, si no se tiene cuidado, la decadencia que ha afectado a Italia, España y Portugal, en resumen a las naciones católicas y latinas de Europa, arriesga acentuarse en provecho de las naciones cristianas disidentes -Rusia, Prusia y Turquía- al menos que una nueva alianza bajo el báculo de Napoleón III las regenere. [...] el ascenso de las naciones protestantes y de la raza anglosajona es tanto más evidente que en América [...] Es tiempo de unirse en Europa para ayudar a las naciones 'latinas', hermanas de América, para encontrar esa vía de progreso que Francia ha descubierto por sí misma"5.

3 CHOQUEHUANCA, David, Secretario Ejecutivo del ALBA ATP, Caracas, 10/08/2017 en DOSSIER, VTV: https:// www.youtube.com/watch?v=FUf48UiOanQ\&list=PLAuUAmNdy82U5DGqqjelwM1wX4QTdU6Ow

4 CHAVALIER, Michael, Cartas sobre América del Norte, París, 1836, en NEIRA, Hernán, "Latinoamérica" ... op. cit., p. 588.

5 MARTINIÈRE, Guy, Les Amérique latines, Grenoble, Presses de I'Université de Grenoble, 1978, en NEIRA, Hernán, "Latinoamérica" ... op. cit., p. 588. Ver también: ARDAO, Arturo, Nuestra América Latina, Ediciones de la Banda Oriental, Temas Latinoamericanos, Montevideo, 1986, ps. 40-41. 
No obstante, son los intelectuales de la región quienes comienzan a usar el término, dándole validez a pesar de que el mismo desconoce a otros grupos étnicos importantes de la región como indígenas y afroamericanos. Entre los primeros que utilizaron este término se encuentran José María Torres Caicedo $(1851)^{6}$, Francisco Bilbao (1856), Carlos Calvo (1862) y José Enrique Rodó (1900). Este y muchos otros términos paradójicos se pueden encontrar dentro de la historiografía y sociología de la región, y como señala Hernán Neria, "contribuye [...] a velar el hecho de que al menos una parte importante de la consciencia de sí americana es reflejo de la consciencia que Europa tiene de América"7.

Por tanto, la impronta epistemológica europea ha sido muy difícil de superar, a pesar de las voces disidentes que siempre han existido, y a pesar de que en algunos momentos históricos han ocupado un lugar importante, a veces aparecen fragmentadas o terminan por ser acalladas por los grupos en el poder que imponen su visión de la historia8. De allí, otro elemento a ser considerado en este artículo es el relacionado con la identidad, y en consonancia con Gabriel Salazar, independientemente de "la naturaleza específica de los procesos históricos locales, la clave de observación y el análisis e interpretación de los mismos han pertenecido caso a caso, a la lógica y perspectivas propias de ese universo cultural" 9 al que se denomina occidental.

Igualmente, hay que destacar que la periodización, la epistemología y la metodología que utiliza la historiografía latinoamericana de las Relaciones Internacionales "revela la adscripción categorial" de occidente, absorbiendo su ethos civilizatorio tanto en el discurso académico, como en el político con algunas excepciones que también serán abordadas. Es importante destacar que cuando se habla de historia se hace referencia a "lo sucedido, el conocimiento de lo sucedido y lo registrado sobre lo sucedido" ${ }^{10}$, mientras que por historiografía se entiende "al cuerpo de escritos que registra los hechos y aconteceres"11. En este sentido hablar de historiografía latinoamericana de la relaciones internacionales indica el esfuerzo de utilizar los recursos históricos para entender la inserción internacional de la región, determinar su condición y el porqué de esa condición, viendo hacia atrás para explicar el presente.

Una vez clarificadas estas ideas, resulta vital indicar que cuando se aborda una historiografía latinoamericana de las Relaciones Internacionales es ineludible reconocer como los principales antecedentes a las historiografías nacionales de los estados latinoamericanos

6 "Desde 1851 empezamos a dar a la América española el calificativo de latina". En TORRE, Caicedo, Mis Ideas y mis principios, París, 1875 p.151. ARDAO, Arturo, Nuestra América Latina, Ediciones de la Banda Oriental, Temas Latinoamericanos, Montevideo, 1986, p. 40.

7 NEIRA, Hernán, "Latinoamérica" ... op. cit., p. 589.

8 Arturo Andrés Roy señala cómo Eduardo Devés presenta evidencias de "la confrontación 'europeísmoamericanismo' como un movimiento alternado y oscilante históricamente de desdibujamiento de una identidad como consecuencia de la nivelación que impone constantemente nuestra incorporación a la modernidad" en DEVÉS, Eduardo, El Pensamiento Latinoamericano en el Siglo XX. Entre la Modernidad y la Identidad. Del Ariel de Rodó a la CEPAL, Tomo I, Editorial Biblos, Centro de Investigaciones Diego Barros Arana, Buenos Aires, 2000, Prólogo, p. 9

9 SALAZAR, Gabriel, "Historia" en SALAS ASTRIAN, Ricardo (Coord.) op. cit., p. 519.

${ }^{10}$ ESCANDÓN, Patricia "Cartas, Diarios y Memoriales del periodo colonial como material historiográfico" en Anuario de Estudios Latinoamericanos, Universidad Autónoma de México, n 3, México, 2002, p. 204.

${ }^{11}$ GAOS, José, "Notas sobre la historiografía" en Historias, Boletín de Información de Investigaciones Históricas, UNAM, n 6, mayo-agosto, 1981, p. 23. 
y la Historia de América. Además de las contribuciones que las diversas disciplinas de las ciencias sociales (la Filosofía, la Antropología, la Sociología, la Política y la Economía) hicieran valiéndose de los datos históricos y de los métodos de la historia para realizar una mejor comprensión, análisis, teorización y explicación de las relaciones internacionales de América Latina $^{12}$.

\section{Nacimiento de la historiografía latinoamericana y su influjo en las relaciones internacionales de la región}

La Historia ha cumplido una importante función en el desarrollo teórico práctico de la disciplina de las Relaciones Internacionales, en tanto que los textos históricos más relevantes han dado testimonio de las relaciones de poder entre los pueblos antiguos. La Historia ha funcionado como lo que Fernando Savater denominó "remedios simbólicos" de las "máquinas de inmortalidad"13 que son las sociedades. Así, los textos históricos más antiguos conocidos, las listas o crónicas de reyes, relataban acontecimientos "cuya función era legitimar el poder y justificar el derecho divino"14 de los reyes.

En la historiografía latinoamericana, no ha sido diferente, esta tiene sus antecedentes en las narraciones del siglo XVI que relataban la conquista de América, las cuales tenían un eminente carácter político, pues los autores de dichos relatos no eran historiadores sino "exploradores, soldados, funcionarios y religiosos"15 europeos. Estas narraciones contaban con rasgos heterogéneos, fragmentados en tanto no se referían a las Indias Occidentales en su totalidad, sino que emanaba de cronistas de áreas geográficas específicas, y estaban impregnadas de un estilo novelístico, pictórico, metafórico, no así de rigurosidad científica. Se asumía un discurso retórico, descriptivo, muchas veces recogía los relatos orales de proezas heroicas, prodigios milagrosos que contenían una mezcla de verdad con ficción, en los que predomina la cosmovisión europea. Estos documentos que conforman la historiografía de las Indias Occidentales, están compuestos por crónicas, cartas y diarios de navegación, leyes de indias, entre otras. Sin embargo, existen algunos relatos escritos por mestizos o indígenas ${ }^{16}$ que describen el punto de vista del otro, del conquistado.

Con los procesos de independencia, durante el siglo XIX, aparecen las historiografías

${ }^{12}$ Cabe destacar que ha sido frecuente el uso combinado de disciplinas de las ciencias sociales y de la Historia por los intelectuales latinoamericanos, para explicar la realidad latinoamericana, así la inserción internacional y el comportamiento internacional de los estados de la región han sido estudiados desde la Relaciones Internacionales, la Economía Internacional, la Sociología, la Ciencia Política y la Filosofía recurriendo a la Historia, sus fuentes y sus métodos, de allí se han generado líneas de pensamiento novedosos y propios de la región como la Filosofía de la Liberación, las teorías de la dependencia, el pensamiento decolonial, los cuales hacen sus propias interpretaciones de la historia y del pasado de la región. Por ello Rapoport al referirse a la Historia de las Relaciones Internaciones afirma: "más que una disciplina es sobre todo un área interdisciplinaria donde confluyen la diplomacia, la economía, la geografía, la demografía, las ciencias políticas y sociales, el estudio de las instituciones, el análisis comparado", en RAPAPORT, Mario, "Una contribución al estudio de la historia de las relaciones internacionales en América Latina desde el siglo XX", 2005, p. 92: http://www.mariorapoport.com.ar/ uploadsarchivos/horizontes_latinoamericanos.pdf [Consultado el 15 de noviembre de 2017].

13 SAVATER, Fernando, Política para Amador, Editorial Ariel S. A., Barcelona, 1997, p. 32.

${ }^{14}$ GUERRA, Cristina, "Modelos Epistemológicos y metodológicos en el desarrollo de la historia", p. 2. Disponible en: http://www.didacticadelahistoria.unlu.edu.ar/sites/www.didacticadelahistoria.unlu.edu.ar/files/site/

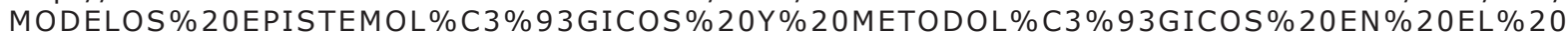
DESARROLLO\%20DE\%20LA\%20HISTORIA.pdf

${ }^{15}$ ESCADRÓN, Patricia "Cartas, Diarios... op.cit., p. 205.

${ }^{16}$ Por ejemplo el Inca Garcilaso de la Vega. 
independentistas, una historiografía política enmarcada en el realismo político, teoría tradicional de las relaciones internacionales, y que coinciden con el surgimiento de la llamada historia científica ${ }^{17}$. La crónica es desplazada por la investigación basada en la objetividad y el método, propio de la perspectiva teórica de la Ilustración, es decir, que desde el comienzo la historia de la región se registró con el sello occidental, el cual se hace evidente en la periodización que asumen los historiadores: descubrimiento, conquista, colonia, república. Los procesos de independencia que en lo político significó una ruptura con la metrópolis colonial, en lo cultural no significó la ruptura con el paradigma epistemológico europeo, a pesar de que personajes como Andrés Bello, Simón Rodríguez y otros, en su momento alertaron sobre la necesidad de una independencia cultural. No obstante, las historiografías nacionales que se fueron configurando en la región durante el s. XIX se mantuvieron dentro de ese paradigma.

"La historiografía del Siglo XIX asumió la llegada de la modernización industrial (origen nord-atlántico) de un modo no demasiado diferente a cómo los independentistas de 1810: no en son de ruptura sino de continuidad. De esta manera el secularismo y el industrialismo sajones fueron agregados marginalmente del modelo cultural latino"18.

De tal manera que las nuevas repúblicas se crean sobre la base del sistema colonial, sus instituciones, sus fronteras, sus historias y sobre la pretensión de alcanzar la consolidación del estado-nación moderno europeo como modelo universal, dejando atrás las ideas unitarias de Francisco de Miranda, Bolívar, San Martín, O 'Higgins ${ }^{19}$, de crear un continente confederado, unificado, con un ideal común que hiciera frente a Europa y a Estados Unidos de Norte América. Una de las constantes de la historia de la región será ese enfrentamiento de ideas entre la patria chica y la patriagrande, entre la integración y el separatismo individualista ${ }^{20}$.

Los historiadores de la segunda mitad del siglo XIX y principios del XX no introdujeron cambios sustantivos en cuanto a jerarquías de valores, temas y locus epistemológico desde el cual relataron y se aproximaron a los procesos políticos. La innovación ocurrió en el plano metodológico con la adopción del positivismo empirista ${ }^{21}$ e institucional, con la consolidación

17 AROSTEGUI, Julio, La investigación histórica, Teoría y Método, Editorial crítica, Barcelona, 1995.

18 SALAZAR, Gabriel, Pensamiento Político..., op. cit., p. 520.

${ }^{19}$ Quienes formaban parte de las sociedades secretas masónicas, tenían un sentimiento antihispánico desde una perspectiva más mundial, el proyecto de formar un gran país comercializador y relacionarse directamente con Europa y EEUU, además de estratégicamente tener una mayor correlación de fuerza con estos.

${ }^{20}$ La confrontación de posiciones divergentes se originan desde el mismo proceso de independencia, autonomía o independencia, liberalismo o conservadurismo, centralismo o federalismo "que trajo consigo periodos de guerras civiles y crisis políticas en muchos países de la región, dando origen a estados débiles y anarquizados internamente", justamente lo que trataron de evitar los líderes de la Independencia que idearon la integración como mecanismo de fortalecer a las naciones nacientes frente a los peligros externos. "Ese era el sentido que le otorgaba Simón Bolívar a la convocatoria del Congreso de Panamá en 1826: crear una Confederación de Estados que pudiera hacer frente a todos los peligros que atentaban contra las nuevas naciones. Y aunque la fragmentación, las desconfianzas y las disputas entre países, además de los problemas internos y las divergencias sobre el papel de EEUU, no permitieron que se realizara la unión en los términos vislumbrados por Simón Bolívar, sí logró que se iniciara la configuración del Sistema Interamericano" con la creación de la Unión Panamericana en 1910, la cual fue sustituida posteriormente, en 1948, por la OEA. VILLARROEL PEÑA, Yetzy, "América Latina y su papel en la configuración del Derecho Internacional", Revista Politeia, vol 36, n 46, IEP, UCV, Caracas, 2011 , ps. 111-114.

${ }^{21}$ SALAZAR, Gabriel, Pensamiento Político..., op. cit., p.520. El positivismo latinoamericano no fue homogéneo, pero en todos anidaba la idea de alcanzar el progreso y la civilización que encarnaban los modelos de EEUU y Europa, abandonando a barbarie propia de la región y resultado del legado español, la deslatinización de 
universitaria de la disciplina, dejando de lado el romanticismo que predominó a mediados del siglo XIX y que recrea las gestas heroicas de los padres de la patria, que luego darán origen a los caudillos como expresión política de la región, sin que con ello dejara de traslucir la concepción heroica de la historia, ni la mitificación de la nación que la documentaciones oficiales revelaban.

Esta situación hizo difícil que se produjera una Historia Latinoamericana, desde el momento de la independencia, sino que se empezara a gestar casi finalizando el s.XIX, en tanto que lo que predominó fueron las historias nacionales y estas sirvieron de insumo para dar origen a lo que se llamó Historia de América de América como campo de estudio universitario. La primera Historia de América la escribió el chileno Diego Barrios Arana en 1865, que aunque fue un paso importante, sólo constituyó una compilación de las historias de cada estado de la región, sin un análisis profundo de las cuestiones comunes, sin estudiarla como un objeto de estudio que permitiera una mirada global del conjunto.

Quienes se esforzaron por hacer una línea de investigación sobre la historia de Latinoamérica, fueron paradójicamente intelectuales estadounidenses y europeos. Los estudios latinoamericanos y los centros de investigación sobre América Latina en los EEUU se produjeron entre mediados del siglo XIX y comienzos del XX, pues, era un objeto de estudio importante para la geopolítica de este país, para establecer sus estrategias de política exterior sobre la región y para ejercer de la mejor manera la Doctrina Monroe. La Universidad de Berkeley contaba en 1922 con la cátedra "La Gran América" de Herbert Bolton, en la cual se hacía el estudio de la región con una idea unificada del Hemisferio Occidental22, lo cual no indica que no hubiera iniciativas dentro de la región para estudiar Latinoamérica como un todo, sólo que estas eran escasas y desconectadas. Por ejemplo, el brasileño Rocha Pombo realizó un avance al respecto al editar el Compendio de Historia Americana iniciando el siglo $\mathrm{XX}^{23}$.

En Europa se creó en 1874 la Sociedad Americanista, específicamente en Francia, y los Congresos americanistas para intercambiar interpretaciones sobre el mundo exótico americano por intelectuales europeos, siendo denominado por Edmundo Heredia como "imperialismo científico"24.

La mayoría de los registros historiográficos que pueden tomarse como estudios internacionales de la región están referidos a cuestiones limítrofes originadas a partir de la independencia, que corresponden a reclamos entre vecinos sobre posesiones territoriales y por incursiones de potencias extranjeras en los territorios emancipados de España. Dichos registros, generalmente no son realizados por historiadores sino por diplomáticos, militares o abogados,

América a cambio de su sajonización, siendo la educación, la política y la religión donde mayor énfasis hizo la acción histórica positivista. Entre los pensadores positivistas latinoamericanos se pueden señalar a Juan Bautista Alberdi, José María Luis Mora, Domingo Faustino Sarmientos, César Zumeta, Justo Arosemena, Eugenio María de Hostos, entre otros. ZEA, Leopoldo (Comp.), Pensamiento Positivista Latinoamericano, Biblioteca Ayacucho, Tomo I y II, n 71- 72, Caracas, 1980.

22 HANKEL, Lewis, "¿Tienen las Américas una Historia común? Crítica a la teoría de H.E. Bolton", Anuario, Facultad de Humanidades y Educación, Tomo I, Caracas, 1964.

23 POMBO, Rocha, Compendio de Historia de Americana, Río de Janeiro, Laenment e Co., 1900.

24 HEREDIA, Edmundo, "Relaciones Internacionales Latinoamericanas: historiografía y teorías" en Estudios Iberoamericanos, PUCRS, v. XXXIV, n 1, 2008, p. 13. 
recogidos en la llamada Historia Diplomática y en los estudios geopolíticos y jurídicos ${ }^{25}$.

No obstante, a mediados del siglo XX se produjeron una serie de circunstancias que favorecen la concepción de la disciplina internacional y de estudios que explicaran las relaciones internacionales de la región. La crisis del capitalismo de $1929^{26}$ y las dos guerras mundiales, permitieron enfatizar la necesidad de autonomía económica y de crear estudios sobre y desde la región, a la par que permitió el surgimiento de las ciencias sociales latinoamericanas, la CEPAL, las carreras de Relaciones Internacionales a partir de 1960 en distintas universidades de América Latina, así como revistas especializadas, "pero sobre todo la necesidad de crear teorías autónomas que permitieran reducir y tal vez eliminar los niveles de dependencia política, económica e intelectual" 27 .

Afirma el historiador peruano Fernando Iwasaki que no hubo historiografía nacional de la región durante los años sesenta, que no concluyera que la independencia sólo fue una continuación del sistema colonial, mostrando el fracaso de las burguesías nacionales que instauraron regímenes autoritarios, que convirtieron las economías de sus países en economías de enclave, productoras de materias primas y que promovieron el exterminio indígena para favorecer la migración europea. Coincide con la emergencia de los movimientos revolucionarios que ante este diagnóstico proponían la emergencia de un estado popular ${ }^{28}$.

Luego de la II Guerra Mundial y ante la exigencia de crear un Nuevo Orden Internacional (NOI), se produce la época de oro del pensamiento latinoamericano y con ello una formulación teórica y metodológica de las Relaciones Internacionales de América Latina que no ha cesado aunque ha tenido sus altas y bajas, las concepciones cepalistas (1950), la teoría de la dependencia (1960)que se apoyó en el método histórico, la filosofía de la liberación (1970), y posteriormente el pensamiento decolonial (finales de 1990) ${ }^{29}$, siempre desde el pensamiento crítico. Los teóricos de la dependencia, además del método histórico estructural, se enfocaron en las relaciones económicas, sociales, políticas e históricas, para comprender cómo se produce la inserción internacional de la región, las razones del atraso económico (subdesarrollo), construyendo todo un paradigma interpretativo de la realidad internacional latinoamericana y del llamado Tercer Mundo.

25 VILLARROEL PEÑA, Yetzy, "América Latina y su ..., op. cit., p. 116.

${ }^{26}$ Entre 1929 y 1948, la Escuela de los Annales francesa le dedicó buena parte de su producción al análisis de América Latina, en la cual predominaba directamente la relación economía e historia, la cual influyó primeramente en países como Brasil y Argentina cuyas ideas se propagarían por el resto del subcontinente. MARTINIÈRE, Guy, "La Escuela de los «Annales» y las Américas Latinas (1929-1949)", Estudios Latinoamericanos, vol. 6, 1980, ps. 133-153.

27 VILLARROEL PEÑA, Yetzy, Vigencia teórica de la perspectiva estructural dependentista latinoamericana de las Relaciones Internacionales. Tesis Doctoral. Universidad Simón Bolívar, 2011, p. 70.

28 IWASAKI, Fernando, "Del Estado nación al estado de la nación. Una mirada historiográfica", Conferencia dictada en Casa América con motivo de la celebración de sus 25 años, 27 de abril de 2017: https://www.youtube.com/ watch?v=_hClanwq1BY [Consultado el 15 de noviembre de 2017]

${ }^{29} \mathrm{El}$ pensamiento decolonial o la opción decolonial es un pensamiento crítico que surge a partir de la década de 1990 de una articulación de intelectuales y activistas dentro del Proyecto Modernidad-Colonialidad-Decolonialidad en diálogo con la teoría del sistema mundo de Wallerstain para repensar la historia o las historias de América Latina (Abya Yala) partiendo desde 1492 hasta nuestros días, repensando conceptos, ideas, temas propios de la modernidad, la cual de acuerdo con este esquema de pensamiento no existe sin colonialidad con el propósito de crear una desobediencia epistémica, nuevos paradigmas, nuevas epistemologías que den cuenta de la mejor manera de nuestra realidad. Entre sus pensadores se cuenta Enrique Dussel, Walter Mignolio, Aníbal Quijano, Edgardo Lander y muchos otros más. Están enmarcadas entre las llamadas Epistemologías del Sur sobre las que piensa Boaventura de Sousa Santos, aunque tiene sus diferencias. 
"Las reflexiones desde América Latina, bajo la perspectiva estructuralista y dependentista, se hicieron tomando en consideración que el nacimiento de los Estados latinoamericanos, como miembros de la comunidad internacional moderna, fue 'marginal, incompleto y eclético' (Tomasini, 1990:284)" 30.

Y se realizó dentro de un sistema internacional jerárquico, con relaciones asimétricas, en el que América Latina le correspondió ser el productor de materias primas, perteneciente a una periferia subdesarrollada que gira en torno a un centro desarrollado e industrializado. Oswaldo Sunkel al referirse al método histórico estructural del que parte Raúl Prebisch, y posteriormente, los teóricos de la dependencia, sostiene:

"Su formulación no es apriorística, no es sobre la base de decir el comportamiento humano es maximizador, que es la fórmula que está detrás de todo el pensamiento económico contemporáneo moderno, sino al revés, de dónde surge esta configuración histórica que está más allá, cuál es la diferencia por ejemplo de la forma como se ha desarrollado Europa, EEUU, América Latina. Esa formación histórica conduce a interpretaciones completamente diferentes y a realidades completamente diferentes y a formulaciones de política económica completamente diferente." ${ }^{\prime 31}$

Una vez creada la disciplina de las Relaciones Internacionales en la región, estudiosos de la Historia como Edmundo Aníbal Heredia, Mario Rapoport ${ }^{32}$, Amado Luiz Cervo ${ }^{33}$, Demetrio Boersner, entre otros, asumieron la responsabilidad de realizar una interpretación histórica de las Relaciones Internacionales desde América Latina, confrontando las visiones históricas nacionales y direccionándolas hacia historias con visiones globales de la región. Así la Historia de las Relaciones Internacionales latinoamericanas tiene una fuerte deuda con las historias nacionales, con el Derecho, pero también con el resto de las ciencias sociales como la Filosofía, la Sociología, la Geografía, la Economía, la Antropología y la Política, que permitieron ampliar el horizonte epistemológico conceptual, distinguir un objeto de estudio bajo el nombre de América Latina a lo largo del tiempo como un todo complejo de fenómenos de interrelación entre naciones y pueblos.

Edmundo Heredia sostiene que para comprender la Historia de las Relaciones Internacionales de América Latina se debe asignar gran atención a la dimensión espacial de las Relaciones Internacionales, la cual involucra "la existencia de regiones inter nacionales, regiones de frontera, regiones culturales, regiones subterráneas, naciones intermediarias" ${ }^{134}$ y con ello determinar el papel que juegan las poblaciones en la configuración de estas múltiples relaciones que las convierten en actores internacionales, lo que "implica abrir hipótesis en los estudios concretos que reconozcan la existencia de relaciones-inter-regionales superpuestas

30 TOMASSINI, Luciano citado por VILLARROEL PEÑA, Yetzy, Vigencia del Pensamiento..., op. cit., p. 10

${ }^{31}$ SUNKEL, Oswaldo, "Raúl Prebish y los desafíos del desarrollo del siglo XXI", CEPAL, 23 de marzo 2013: https:// www.youtube.com/watch?v=qGrsBqIaoD0

32 RAPOPORT, Mario, "Una contribución al estudio..., op. cit, ps. 91-102: http://www.mariorapoport.com.ar/ uploadsarchivos/horizontes_latinoamericanos.pdf [Consultado el 15 de noviembre de 2017].

${ }^{33}$ CERVO, Amado Luiz, Relações internacionais da América Latina: velhos e novos paradigmas, Saraiva, São Paulo, 2007.

${ }^{34}$ HEREDIA, Edmundo, "Relaciones Internacionales ... op. cit., p. 21. 
y recíprocamente incidentales con las relaciones internacionales propiamente dichas"35.

Heredia y muchos otros intelectuales latinoamericanos, advierten que cuando se tenga una interpretación propia de la realidad latinoamericana se podrán abandonar ideas acerca de similitudes con el resto del mundo, y esto parte de elaborar teorías y conceptos inspirados en la propia realidad histórica y en las propias peculiaridades y originalidades regionales. Además, que al considerar la dimensión espacial y étnica en el desarrollo de las relaciones internacionales de la región, los planteamientos teóricos deberían dirigirse hacia las relaciones inter-étnica y relaciones inter-regionales, en tanto que estas categorías pueden ser desde el punto de vista explicativo, más exactas que el que solo se refiere a las relaciones entre naciones ${ }^{36}$.

Igualmente, ha habido corrientes historiográficas que se sustentan en la Sociología, la llamada historia sociológica, que no solo se centra en las iniciativas políticas o diplomáticas de quienes toman decisiones, sino que analiza también lo que Renouvain denominó fuerzas profundas, las de carácter colectiva, impersonales y socioeconómicas ${ }^{37}$. Allí radica la originalidad de los análisis en Relaciones Internacionales latinoamericanos, en esa amalgama perfecta que hace de todas las disciplinas de las ciencias sociales latinoamericanas para comprender su propia realidad histórica e internacional.

En consonancia con esto, Enrique Dussel, desde su postura decolonial afirma una visión de la historia no eurocéntrica:

"tengo que reconstruir la historia mundial para empezar a poder ser latinoamericano y pensar desde mi horizonte [latinoamericano] las cosas [...] La Historia es el horizonte epistemológico último de las ciencias, aun de la matemática, porque también hay la historia de la matemática" 38 .

De allí la importancia que adquiere el estudio histórico en la actualidad dentro de las Relaciones Internacionales y demás disciplinas de la región, pues requiere la constante reflexión crítica ante la avalancha de hechos que propician transformaciones de los sistemas internos latinoamericanos pero también del sistema internacional, y estos estudios críticos son los que pueden dar las claves para generar cambios o continuidades que permitan una inserción internacional justa y con ganancias en términos de avances sociales, políticos y económicos para la región.

\section{Papel de la Historia en la configuración de las identidades de la región y su impacto en el comportamiento internacional, mediante imaginarios sociales y conciencia colectiva}

A mediados del siglo XVIII e inicios del siglo XIX, en el continente americano se acentúa la curiosidad por el conocimiento, por los nuevos descubrimientos, por las novedosas ideas

\footnotetext{
35 Ibídem.

${ }^{36}$ Ibíd.

37 BOERSNER, Demetrio, Relaciones Internacionales de América Latina. Breve Historia, Editorial Nueva Sociedad, Caracas, 1990 [1era. Ed. 1982].

38 DUSSEL, Enrique, "El giro decolonizador" entrevista, Noruega 18 al 21 de abril de 2012: https://www.youtube. com/watch?v=mI9F73wIMQE [Consultado el 20 de octubre de 2016].
} 
provenientes de la Ilustración; las ideas de Rousseau, Voltaire y Montesquieu son la fascinación del criollo ansioso de saber ${ }^{39}$. Todas las reflexiones que los pensadores europeos de la época hicieron sobre sí mismos y el mundo que los rodeaba, se convirtió en el continente americano en el referente principal para construir la ciencia histórica latinoamericana ${ }^{40}$.

Surge un gran número de intelectuales que comienzan a tejer el ideal de crear en América una república autónoma, rectora de su propio destino; comienzan a valorar las virtudes naturales de la región, los mitos de origen indígena ${ }^{41}$ y a apreciar la riqueza de la cultura local, lo que comienza a gestar un americanismo ascendente. Figuras como las de Francisco de Miranda, Andrés Bello y Simón Rodríguez en Venezuela, Juan Egaña, Javier Eugenio Espejo en Chile, Antonio Nariño en Colombia, el jesuita Clavijero en México ${ }^{42}$, destacan como algunos de esos intelectuales del siglo XVIII que iniciaron la corriente hispanoamericanista, posteriormente llamada latinoamericanista.

Todos ellos, de alguna u otra forma, legaron sus obras reformadoras para la construcción y articulación de una conciencia de unidad hispanoamericana. En todos los "documentos de la primera insurgencia, la palabra América, la 'unidad y fraternidad de los americanos' prevalece" emergen las primeras expresiones nacionalistas articuladas como proyecto en América Latina. Sin embargo, esto no niega la existencia de otros tipos de identidades entre los grupos humanos existentes en la región, pero pareciera que es a través de estos precursores del proceso de independencia que se hace por primera vez en América Latina, el esfuerzo de generar una identidad nacional propia, entendiendo como nación a toda América y también de allí emerge otra constante la preocupación, tanto teórica como práctica, del continente en torno a la integración regional y la manera de lograrla o la aceptación de la región como zona de influencia de los Estados Unidos y sus respectivas consecuencias en términos de

39 Uno de los reproches que hacen los criollos americanos a la metrópoli española es la censura y bloqueo de la información proveniente de Europa, además del poco esfuerzo que se le atribuía a la formación de la juventud colonial, dejándolos en el más profundo oscurantismo. Contaban con muy pocas escuelas y universidades y el principal tema de los textos escolares era de orden religioso. Aunque hay que reconocer que en los dominios políticos territoriales denominados Virreinatos, la educación fue un poco más esmerada, pero siempre con un cuidadoso control sobre la información que llegaba a manos de los colonos. Respecto a la educación durante la época colonial ver RODRÍGUEZ, Simón, "Reflexiones sobre los defectos que vician la escuela de primeras letras de Caracas y Medios de lograr su reforma por un nuevo establecimiento", en CHIARAMONTE, José, Pensamiento de la Ilustración. Economía y Sociedad Iberoamericana en el siglo XVII, Biblioteca Ayacucho, Caracas, $2^{a}$ ed., 1992, ps. 372-397; y SANZ, José Miguel, "Informe sobre educación pública durante la colonia", en CHIARAMONTE, Carlos, Pensamiento de la... op. cit., ps.395-397.

40 PICÓN SALAS, Mariano, Dependencia e independencia en la historia hispanoamericana, Ediciones Cruz del Sur, Caracas, 1952. p. 16. Uno de los autores más leídos durante ese período fue el Ministro de Carlos III de España, Pedro Rodríguez de Campomanes, quien destacó como promotor de muchas de las reformas del reinado borbónico en sus colonias. "Criticó con dureza la política comercial de España, su sistema mercantil, la política aislacionista hacia las colonias americanas (...) España debía fundar un gran centro de estudio para los americanos, darles en la Península cargos y prebendas, (...) fomentar 'la amistad y la unión para formar un solo cuerpo de nación'." LEAL, Ildefonso, Nuevas Crónicas de Historia de Venezuela, Academia Nacional de la Historia, Tomo I, no 37, Caracas, 1985, p. 270. Es, pues, "el grado de innovación de la cultura católica española y en alguna medida europea, el que induce y a la vez marca los límites de avances de la mayor parte del pensamiento criollo preindependentista del siglo XVIII". CHIARAMONTE, José, Pensamiento de... op. cit., p. xvii.

41 "Los padres Clavijero, Juan de Velasco, Ignacio Molina, José Manuel Peramas, Gily, entre otros, destacaron una entusiasta apología del indio y una rehabilitación de la naturaleza y de la inteligencia de los americanos." LEAL, Ildefonso, Nuevas Crónicas... op. cit., p. 296. CHIARAMONTE, José, Pensamiento de... op. cit., ps. xv-xvi.

42 PICÓN SALAS, Mariano, Dependencia e independencia... op. cit., ps. 8-63.

${ }^{43}$ Ibídem, p. 67. 
soberanía, crecimiento económico e inserción internacional.

No obstante, la formación de ese vínculo en América Latina fue lenta, a pesar de los esfuerzos que representaron las ideas de los intelectuales de mediados del siglo XVIII e inicios del siglo XIX, debido a la complejidad de la estructura socio-cultural de la América colonial ${ }^{44}$. En el momento histórico al que se hace referencia es difícil determinar el estado de la cuestión nacional, pues se puede comprender que cada grupo social debía tener algún tipo de identidad social pero no articuladas en una unidad ${ }^{45}$.

Aunque en todas las excolonias parecía un común denominador el compartir la idea de una patria grande que agrupara a todos los americanos, la separatividad en que España mantuvo a sus provincias coloniales, hizo difícil que ésta prosperara. El resultado final fue de 18 naciones soberanas en lugar de la gran nación americana. Esa misma condición de separatividad que había entre las excolonias, existía también a lo interno de cada nación. Una vez creado el estado se gesta un nacionalismo cultural elitesco que emanaba de un grupo selecto de intelectuales, no así del grueso de la población del continente. Este grupo selecto, generalmente vinculado al poder desde la historiografía, contribuyó a la construcción de imaginarios sociales, representaciones colectivas y a la exaltación del orden triunfante ${ }^{46}$.

Durante el siglo XIX, las élites nacionales se esforzaron por europeizarse; una especie de síndrome que Jorge Abelardo Ramos llamó "una anglomanía o francomanía lugareña"47, que durante el siglo XX se convirtió en americanomanía, haciendo referencia a los Estados Unidos, lo que demuestra la existencia de un grave problema de identidad que se viene arrastrando desde la independencia; de tal forma que en muchas ocasiones las élites nacionales se han comportado "como el orangután que imaginaba Blanco Fombona que al imitar a su amo mientras se afeitaba, terminó por degollarse con su navaja." 48

${ }^{44}$ El sistema social creado por el sistema colonial se caracterizó por su rigidez, "la formación de la nación y el proyecto de la nación propuesto por las clases ilustradas del siglo de las luces (...) suponía la ampliación de la libertad, la modernización de la sociedad, la estructura social menos rígida (...) el acercamiento de las clases a consecuencia de la eliminación de las barreras de castas, la liquidación o debilitamiento de la esclavitud y (...) los patriotas que dirigían los Estados surgidos de la guerra de independencia dieron sólo un pequeño y formal paso hacia la integración social dentro del marco de la libertad". LEPKOWSKI, Tadeusz, "Formación de nacionalidades en América Latina (1780-1830). Reflexiones generales y algunos casos específicos", Congreso Bicentenario de Simón Bolívar, Academia Nacional de la Historia, Caracas, 1983, tomo III, p. 45. En lo cultural se pasa de una revisión de la cultura por el colonialismo y de la nativa. Una vez alcanzada la independencia la cultura hispanoamericana se ve permeada por la francesa y la inglesa. SOLER, R. Ideas de la cuestión nacional latinoamericanas de la emergencia del imperialismo, México, 1980.

45 "Los criollos blancos se sentían americanos y en su opinión tenían dos patrias: la local y la de su nivel superior (...) 'de administración colonial' (...) Los indígenas a su vez seguían considerando a los criollos y los indígenas descendientes de los conquistadores (...) En general, los criollos y los indígenas no compartían las mismas idea de patria. Ninguno (...) tenía conciencia de pertenecer a la misma comunidad nacional o por lo menos prenacional(...) el caso de los esclavos negros es parecido". LEPKOWSKI, Tadeusz, "Formación de nacionalidades... op. cit., p. 44. Más complejo aún sería el caso de los mestizos y mulatos quienes compartían un poco de cada uno de los grupos mencionados.

${ }^{46}$ ANSALDI, Waldo, "Entre perplejidades y angustias. Vota para pensar las Ciencias Sociales Latinoamericanas", 2015, p.16. "La Historiografía se institucionalizó rápidamente en las Academias Nacionales de la Historia, casi siempre paripassu el proceso de construcción del Estado, su enseñanza profesional se estableció mucho más tarde en las Facultades de Filosofía". Ibídem.

47 Primer Congreso del Pensamiento Político Latinoamericano, Ediciones del Bicentenario del Natalicio del Libertador Simón Bolívar/ Congreso de la República de Venezuela, Tomo II, Vol. I, Caracas, 1983, p. 237.

${ }^{48}$ Ibídem. 
El estado en Latinoamérica surge en medio del influjo del pensamiento político liberal, copiando la estructura de los estados occidentales, pero bajo la modalidad de estado oligárquico, para iniciar el proceso de modernización. Una vez constituido el estado surgió la necesidad de crear la nación, lo que no había sido posible gracias al sistema de castas y razas auspiciada por la forma de colonización empleada por los españoles en los territorios latinoamericanos. Para lograr este cometido los líderes políticos recurrieron a la ideología nacionalista o idealización del estado, cimentada en la historia política ${ }^{49}$ y narrativa de la gesta independentista, en la simbología, los rituales patrios y la exaltación de tradiciones culturales, como una forma de crear la idea de unidad y homogeneidad cultural en la nación.

Durante el siglo XIX, el nacionalismo se convirtió en el impulso necesario para lograr la libertad de pueblos sometidos al yugo colonial e imperial, pero pronto los grupos en el poder logran debilitar el nacionalismo en su esencia democrática al hacer uso de la ideología nacional, expresada en el proyecto de nación, en función de sus propios intereses. De este modo, el nacionalismo, tras una democracia formal, censitariamente inclusiva, deja de responder a las demandas sociales mayoritarias y encubre el esfuerzo libertador que motivaba a las masas. La libertad que pregona, es la libertad frente a las demás naciones, mas no necesariamente la libertad individual y política. Este fue el destino del nacionalismo que se produjo en algunos de los países de América Latina al momento de liberarse del yugo colonial.

Conformar la nación en América Latina no fue un proceso fácil, debido a la manera tan atípica como éstos emergen al sistema interestatal: 1) Estos países se insertan en el sistema internacional, por un lado declarando su autonomía y soberanía ante terceros y por otro con una marcada dependencia económica y política de las potencias de turno (Inglaterra, Francia y posteriormente EEUU), en la medida en que los estados latinoamericanos nacen endeudados y empobrecidos a causa de la guerra de independencia; 2) La separación por castas impuestas por el gobierno colonial se mantiene una vez emancipados, lo que hace imposible la unidad nacional. ${ }^{50}$

La falta de unidad nacional permitió que se desarrollara en su seno el fenómeno

49 Siendo que el estado en América Latina precedió a la nación, la historia política cumple una función justificadora del pasado y legitimadora de presente en términos de poder, lo cual se logra debido a la íntima relación que existía entre las élites intelectuales y el estado. "Los historiadores en su mayoría pertenecían a la élite y muchos de ellos integraban el aparato estatal burocrático". RIVAS, Ricardo, "El origen de la nación y los historiadores latinoamericanos" en Cuadernos de CISH, vol. 1, n 1, Universidad de la Plata, 1996, p. 58.

50 Por ejemplo, durante el año 1800 las categorías étnicas que prevalecían en Venezuela eran blancos peninsulares y canarios, blancos criollos, pardos, negros libres y manumisos, negros esclavos, negros cimarrones, indios tributarios, indios no tributarios, población indígena marginal. Los pardos a su vez estaban constituidos por mulatos, zambos, mestizos en general y blancos de orilla. BRITO FIGUEROA, Federico, Historia económica y social de Venezuela, Ediciones de la UCV, Caracas, 1974, ps. 160-164. Una vez alcanzada la independencia pierden jurídicamente su condición de casta para pasar a ser ciudadano, pero en el imaginario colectivo difícilmente se puedan borrar con la guerra y con las leyes lo que tres siglos de dominación instauró. De la misma manera sucedió en el resto de América Latina, más aún en aquellas regiones como los altiplanos mesoamericanos y andinos donde la población indígena ya contaba con una alta organización e identidad cultural. "Los indios en América Latina desde la conquista española han tenido un profundo sentido de la diferencia étnica de los blancos y los mestizos, especialmente porque esta diferencia era reforzada e institucionalizada por el sistema colonial consistente en dividir a la población en castas raciales." HOBSBAWM, Erick, Nacionalismo y Naciones desde 1780, Editorial Crítica, Barcelona, 1991, p. 75. Por tal motivo "resultaba problemático digerir los significados modernos de la libertad (...) en una sociedad de estructura y estratificación tan heterogénea y étnicamente tan dispar." SORIANO DE GARCÍA PELAYO, Graciela, "El sentido de la Historia en dos siglos" en Visiones del siglo XX venezolano, Caracas, Comisión Presidencial V Centenario de Venezuela/CELARG, 8 al 12 de noviembre 1999, ps. 12-13. CARRERA DAMAS, Germán, Una nación Ilamada Venezuela, Monte Ávila Editores Latinoamericanos, 5 ta. ed., Caracas, 1997, p. 76. 
caudillista como mecanismo de los líderes regionales para alcanzar el poder, lo cual sumergió a estos incipientes estados en cruentas y devastadoras guerras intestinas. La dinámica mundial exigía a todos los estados emprender la senda modernizadora al estilo occidental, para lo que se requería de cierta estabilidad política que permitiera la inversión extranjera, lo cual sólo se logrará en el subcontinente americano a través de férreas dictaduras.

Sin embargo, el camino hacia la modernización encontró serios obstáculos en las estructuras preexistentes en estos estados con un modo de producción atrasado, poco eficiente, que no permitía el desarrollo industrial deseado, que se caracterizó por ser monoproductor, principalmente de materias primas. Eran países abiertos al mercado internacional dentro del esquema de crecimiento hacia fuera y por lo tanto sumamente vulnerables ante las fluctuaciones del mercado internacional.

Si bien es cierto que la eliminación de España como intermediario en el intercambio comercial representó para los productores nacionales la obtención de mejores precios por sus productos y la conformación de un sector exportador nacional, también lo es el impacto que produjo la importación de productos procedentes de Inglaterra lo que hizo que la industria artesanal manufacturera legada por la colonia entrara en crisis ${ }^{51}$. Esta situación generó efectos políticos decisivos en el desarrollo de los estados latinoamericanos, pues creó las condiciones para que entraran en conflicto dos fuerzas muy poderosas, por un lado los liberales y por el otro los conservadores.

La dependencia internacional con la que nacen los estados latinoamericanos es descrita por Luciano Tomassini:

"En épocas de recesión, los que no habían recibido los beneficios de la bonanza, perdían su trabajo, pasaban hambre y eran mantenidos a raya por un Estado incipiente, cautivo de esos propietarios, que carecían de administración pero podían ejercer represión.

La tolerancia de la población, en buena parte indígena, tenía raíces históricas y parecía ilimitada. Los grupos adinerados habían acumulado reservas de generación en generación, que le permitía atravesar los períodos recesivos con una capacidad de resistencia igualmente ilimitada." ${ }^{52}$

Dichos estados se definieron como democráticos y liberales copiando el modelo europeo, pero bajo un esquema oligárquico por estar el poder concentrado en una élite producto de la alianza entre terratenientes y burgueses, quienes conservaron las estructuras políticas y sociales coloniales. La alianza de estos grupos de poder dominante se acompañó de un sistema jurídico constitucional que los favorecía exclusivamente a ellos, dejando a las mayorías en completa indefensión y excluidos de los beneficios de la sociedad.

${ }^{51}$ Así lo describe Demetrio Boersner quien sostiene que a pesar de que España y su sistema absolutista no favoreció un desarrollo industrial autónomo en América para finales del siglo XVIII y XIX existía en algunas colonias diversas manufacturas como la industria textil en México, Perú, Chile, Río de la Plata y Brasil. Así como manufacturas especializadas en otros rubros como "elaboración de artículos de metal, cuero y madera". BOERSNER, Demetrio, Relaciones Internacionales de América Latina. Breve Historia, Editorial Nueva Sociedad, Caracas, 1990, [1era. Ed. 1982], p. 128. Ver también CARRERA DAMAS, Germán, Una nación... op. cit., p. 82.

52 TOMASSINI, Luciano, "El Proceso de Globalización y América Latina" en Integración Solidaria: Reconstrucción de los sistemas políticos Latinoamericanos, II, Caracas, USB/IAEAL, 1993, ps. 294-295. 
De acuerdo con esto, los estados latinoamericanos no lograron construir "una sociedad de individuos conscientes de sí, productores y libres, coherente con un verdadero Estado liberal"53. Ante la imposibilidad de explicar el fracaso, y por no contar con mecanismos para minimizar la frustración de la población, a mediados del siglo XIX se recurre al "mito de los orígenes y de la gesta heroica, mito del héroe y culto de Bolívar (de San Martín para el Río de la Plata)"

La fragmentación interna del estado permitió la consolidación del caudillo, cuya figura viene a suplir en las regiones la falta de la internalización de una verdadera identidad nacional, en virtud de que el líder regional representaba la fuerza de cohesión en la región, creando un lazo filial entre sus seguidores y él. Por ejemplo, en Venezuela los caudillos estuvieron representados por personajes destacados en el proceso emancipador, por lo que ante las masas desposeídas, los caudillos se convertían en los herederos genuinos de los ideales de Bolívar, y como tales, los caudillos estaban Ilamados a proporcionarles las mejoras sociales aún no alcanzadas.

Esto no entra en contradicción con el culto a Bolívar como padre de la patria, puesto que no estando éste físicamente, aún quedaban sus ideales y sus compañeros de lucha que venían a sustituir al líder ausente, pero cuyo recuerdo anidaba en la memoria colectiva. Aun cuando en la práctica el caudillo utilizó la fuerza de la movilización popular, en algunos casos fue solo como un trampolín para acceder al poder y no para favorecer la causa popular ${ }^{55}$.

La presencia del caudillo en la historia política de América Latina se mantuvo por mucho tiempo, más aún cuando las reivindicaciones socioeconómicas ofrecidas tardaban en llegar. Cuando el caudillismo es vencido por la fuerza de un estado centralizado, emerge nuevamente, durante el siglo XX, en la figura del líder populista.

Mientras los estados latinoamericanos se encontraban dominados por las oligarquías semifeudales, la hegemonía de Inglaterra las mantuvo bajo una dependencia semicolonial, vulnerando la supuesta independencia política de los estados, que de esta manera se encontraban sujetos a los intereses de las potencias europeas (Inglaterra, Francia, Holanda) que a finales del siglo XIX e inicios del XX, serían desplazados por los Estados Unidos, que logran un desarrollo capitalista animados por una política expansionista a expensas de sus vecinos, especialmente de México, del que extrae en el año 1848 la mitad de lo que fuera su territorio.

Las apetencias territoriales y de dominación de Gran Bretaña, Francia y los Estados Unidos, se dirigen a impedir cualquier idea de unificación entre los países de América Latina, mientras favorecían cualquier proyecto que les permitiera la creación de zonas de influencia para así maximizar los beneficios del desarrollo capitalista. Esta es una de las causas por las cuales, proyectos de unificación como la creación de la Gran Colombia, Capitanía General de

53 SORIANO DE GARCÍA PELAYO, Graciela, "El sentido... op. cit., p. 15.

${ }^{54}$ Ibídem, p.16. También en CARRERA DAMAS, Germán, El Culto a Bolívar (Esbozo para un estudio de la historia de las ideas en Venezuela), Ediciones de la Biblioteca, U.C.V., Caracas, 1993, p. 41.

55 "El patriotismo podía ser unas veces sincero, sería sincero en medio de la enorme confusión de la postguerra, otras, interesado y doblemente manipulador." SORIANO DE GARCÍA PELAYO, Graciela, "El sentido... op. cit., p. 14. 
Guatemala, la confederación entre Perú y Bolivia, entre otros, fueran abortados. Además de que las oligarquías de muchos estados latinoamericanos se asociaron a los intereses de las potencias para obstaculizar estos procesos ${ }^{56}$.

A partir de 1880, Estados Unidos comienza a ejercer un mayor influjo económico y político sobre América Latina como expresión del llamado Destino Manifiesto, según el cual, la región se convertiría en territorio tutelado por Estados Unidos, país que asumiría el papel de protector frente al predominio europeo, de árbitro ante los conflictos interamericanos y de primer socio comercial en las economías. Por esta razón intenta a través de la I Conferencia Internacional Americana ( 2 de octubre de 1889) la creación de una unión aduanera panamericana ${ }^{57}$. Desde ese momento la acción intervencionista de los Estados Unidos en América Latina no dejó de sentirse, siendo su máxima expresión los gobiernos de Teodoro Roosevelt con su Política del garrote, el de Willian Howard Taft y su Diplomacia del dólar, así como el de Woodrow Wilson ${ }^{58}$.

Ente la ineficiencia y la disfuncionalidad del estado liberal oligárquico y las constantes intervenciones extranjeras, la consolidación de la nación en América Latina encontró serios obstáculos. La ansiada modernización no fue posible, pero el desarrollo industrial acelerado del sistema capitalista empujaba a Latinoamérica para que se aventurara a alcanzarlo de cualquier forma.

Ante la necesidad de implementar la modernización del estado que no se había podido alcanzar durante finales del siglo XIX y principios del XX, así como de contener el descontento social, emerge una modalidad de gobiernos en América Latina que se conocen con el nombre de populistas. Los gobiernos populistas son aquellos que utilizan "fórmulas políticas por las cuales el pueblo, considerado como conjunto social homogéneo y como depositario exclusivo de valores positivos, específicos y permanentes, es fuente principal de inspiración y objeto constante de referencia"59. Esta alusión al pueblo y sus virtudes, se producen dentro de una ideología nacionalista, aunque en ocasiones mezclada con otras ideologías como fascismo, socialismo, entre otras.

De acuerdo con lo antes expresado, los movimientos populistas latinoamericanos se producen a partir de 1930, con Getulio Vargas en Brasil (1930), Gualberto Villarroel en Bolivia

${ }^{56}$ Las principales pugnas entre ingleses y norteamericanos se observan en Centroamérica donde se disputan la primacía de crear un canal interoceánico para controlar el comercio mundial. Por otra parte la alianza entre Chile, Argentina y Brasil con Gran Bretaña, permite fortalecer la presencia inglesa en el cono sur, su máxima expresión fueron la Guerra de la Triple Alianza y la segunda Guerra del Pacífico. BOERSNER, Demetrio, Relaciones Internacionales... op. cit., p. 127.

${ }^{57}$ Con esta Conferencia los Estados Unidos se apropia de la idea bolivariana sobre la unión americana adaptándolo a sus intereses y necesidades.

58 Durante estos tres períodos presidenciales Estados Unidos intervino en el Caribe, interviene en Cuba con la Enmienda Platt, en el bloqueo que sufre Venezuela en sus Costas durante el gobierno de Cipriano Castro, en República Dominicana para administrar sus aduanas, presionó a México para que no negociara concesiones con Japón, en Honduras administrando sus aduanas, control del banco nacional de Haití, control de las aduanas de Nicaragua y entrega de dos islas del Golfo de Fonseca por 99 años, convirtieron a Haití en protectorado y establecieron una férrea dictadura estadounidense en República Dominicana. BOERSNER Demetrio, Relaciones Internacionales... op. cit., ps. 183-202.

${ }^{59}$ BOBBIO Norberto, Diccionario de Política, 12a Edición, Siglo XXI Editores, Tomo II, Madrid, 2000, [1era. Ed. en Español 1981-1982], p. 1247. 
(1942), Juan Domingo Perón en Argentina (1943), Juan José Arévalo en Guatemala (1944)60 o Jorge Eliécer Gaitán en Colombia. Éste último no logró alcanzar el poder, pues fue asesinado en 1948, pero la fuerza de movilización que creó fue tan grande que desde ese momento en Colombia no se logró alcanzar la paz social completamente, a pesar de los numerosos intentos de acuerdos de paz.

\section{La perspectiva histórica y las Política Exteriores de los estados latinoamericanos}

En las manifestaciones nacionales de los estados latinoamericanos respecto a sus relaciones con el exterior, especialmente con los países más fuertes, se pueden apreciar políticas exteriores ambiguas que se desplazan entre dos extremos, o bien plegadas a las demandas exógenas, y en ocasiones ansiosos de ser absorbidos por alguna potencia, o bien desplegando momentos eminentemente antiimperialistas.

Las relaciones entre los países de América Latina se han caracterizado por ser ambiguas e inconsistentes, en algunas oportunidades inclinadas hacia la formación de bloques regionales y hacia la cooperación, lo que se evidencia a través de los múltiples tratados suscritos bilateral o multilateralmente entre sí. Sin embargo, estos intentos se ven desarticulados cuando alguna nación o grupos de naciones latinoamericanas apoyan medidas o acuerdos que provienen de Estados Unidos o Europa, y que individualmente les deja beneficios pero rompe con el bloque de poder, debilitando la región. Un ejemplo de esta situación lo constituyó la negociación de la deuda durante la década de 1980, cuando cada estado negoció por su parte en lugar de hacerlo en bloque. También ha sido ambigua la posición de la región durante las frecuentes intervenciones que realizó los Estados Unidos durante los siglos XIX y XX a diferentes naciones de América Latina.

Se puede decir que esa ambigüedad es producto de la ausencia de una conciencia de nación latinoamericana, afianzada y desarrollada sobre la base de los lazos históricos que les unen. El latinoamericano ha mostrado una persistente búsqueda de su idiosincrasia y lo que representa lo propio latinoamericano, pero al mismo tiempo ha insistido en parecerse y adoptar modos de conducta propios de los países más avanzados, en un constante mirarse en el espejo de Occidente ${ }^{61}$, de tratar de definirse conforme a los parámetros que Occidente ha predeterminado y en la cual su imagen se revela distorsionada. Desde el exterior todos son latinos, pero desde el interior de América Latina solo se percibe nacionalidades excluyentes encerradas en sus fronteras e incluso rivales.

${ }^{60}$ BOERSNER Demetrio, Relaciones Internacionales... op. cit., ps. 234-250.

${ }^{61}$ Eduardo Devés describe este proceso como oleadas modernizadoras, en las que los países deciden ponerse al día con los más avanzados, para ello buscan abrir sus mercados a esos países, superar lo condición de atraso mediante la actualización científica y tecnológica. Mientras que las oleadas identitarias se evidencian en necesidad de vivir conforme a su cultura e historia mediantes ritmos autóctonos y autónomos. Este autor explica que a principio del s. XX, por lo menos las tres primeras décadas, se produce una gran oleada identitaria en tres vertientes, "una cultural-arielista, otra social indígena-afroamericanista y otra económico-nacionalista", se va apagando en los años 1930, apareciendo la oleada modernizadora mediante las ciencias económicas y sociales a través de conceptos como "desarrollo, industrialización, cambio social, transición y sociedad moderna, entre otros, y llega a sostenerse durante la segunda mitad del s. XX, paralelamente a un periodo identitario entre 1965 y 1975, que según este autor va a "radicalizar lo modernizador entre los 70 y los primeros 90 con el neoliberalismo" y la emergencia del s. XXI de una reacción identitaria "con la reivindicación global de las culturas." DEVÉS, Eduardo, El Pensamiento Latinoamericano en el Siglo XX. Entre la Modernidad y la Identidad. Desde la CEPAL al neoliberalismo (1950-1990), Tomo II, Editorial Biblos/ Centro de Investigaciones Diego Barros Arana, Buenos Aires, 2003, ps. 14-15. 
Entre los temas privilegiados históricamente en policía exterior está el "decidido interés por la estrategia de América Latina en las negociaciones Norte Sur sobre el Nuevo Orden Económico Internacional; así mismo se buscan alternativas para adquirir mayor autonomía en el sistema internacional y lograr la reestructuración de la economía mundial"62, temas que son más cercanos a la región, que versan sobre su realidad específica y que responden a sus necesidades. Mientras que por otro lado, también ha sido recurrente que países que dentro de la región se sienten en mejores condiciones que se vecinos, intenten acercarse a las potencias de turno como un modo de subir en el statu internacional y lograr mejores condiciones de inserción.

Los estudios estructuralistas, en todas sus versiones, ayudaron a poner el acento en el paradigma que permite entender la realidad internacional, no solo en lo relativo a la inserción internacional, sino también en las modificaciones que el sistema ha manifestado en las décadas posteriores a la instauración de la bipolaridad, lo cual permitió evaluar los límites del paradigma realista dominante, que como afirma Holsti63 es la base de la elaboración y puesta en práctica de la política exterior de las naciones.

En la búsqueda de una mayor y mejor inserción internacional mediante la participación efectiva en la toma de decisiones del sistema internacional y de seguir presionando hacia la construcción de un nuevo orden más justo y equitativo, los científicos sociales latinoamericanos elaboraron a través de las categorías de autonomía y dependencia, una propuesta para la formulación de la política exterior de los estados periféricos. Este enfoque vendría a ser un derivado de todo el trabajo académico elaborado por la CEPAL ${ }^{64}$ y el ISEB, así como de la versión dependentista del estructuralismo latinoamericano en el cual se consideraban algunos puntos de preocupación de estas escuelas de pensamiento como "la dependencia del estado, su carencia de soberanía, el papel de las élites y el potencial de la región"65.

Con el despegue de las ciencias sociales latinoamericanas durante la segunda mitad del siglo XX, se produjeron valiosos esfuerzos por dotar de cuerpo teórico a los entes decisores latinoamericanos de política internacional. Inicialmente, estos esfuerzos se hicieron desde

62 PERINA, Rubén, "Estudios de las Relaciones Internacionales en Universidades de América Latina y el Caribe", en Integración de Latinoamericana, no 81, año 8, 1983, p.39.

${ }^{63}$ HOLSTI, Kalevi Jaakko, The Dividing Discipline: Hegemony and Diversity in International Theory, Houghton Mifflin, Boston, 1985.

TICKNER, Arlene, "Latin American IR and the Primacy of lo práctico" en International Studies Review, vol. 10, Issue 4, diciembre, 2008, p. 739.

${ }^{64}$ El pensamiento estructuralista de la CEPAL proponía, entre otras cosas, recurrir a la integración como mecanismo para alcanzar el desarrollo industrial bajo el esquema de sustitución de importaciones y protección de la industria nacional entre 1960 y 1970, obteniendo diversos resultados y mecanismos de integración. Entre 1980 y 1990 , ante el fracaso de las políticas de ajuste y estabilización macroeconómica, se produce el neoestructuralismo cepalista, como una crítica sobre las estrategias seguidas frente a la crisis del desarrollo y de la deuda, en este marco se proponía la apertura externa sobre la base del denominado regionalismo abierto, que era una suerte de programa de apertura que intentaba conciliar los procesos de liberalización aplicadas por los países de la región hacia el comercio internacional y en un marco de globalización, con el fin de aumentar la competitividad de los países de la región. Esto fue favorecido por las dinámicas de concertación acumulada en la década de 1980 por el Grupo Contadora y el Grupo de Río que permitieron una nueva idea de integración que sin dejar de lado su función económica, asumió evaluaciones de tipo socio-políticas como la concertación de política exteriores, cooperación ambiental, seguridad regional, circulación de personas, entre otras. Pero, además permitió generar una historiografía latinoamericana alrededor del tema de consenso. VILLARROEL PEÑA, Yetzy, Vigencia teórica de la perspectiva estructural dependentista ..., op.cit., ps. 64-65.

65 
la visión economicista para después llegar a posiciones más geoestratégicas y geopolíticas centradas básicamente en el análisis de política exterior, no así en política internacional propiamente.

Por otro lado, es importante no perder de vista que cuando los países de América Latina nacen como estados independientes su política exterior es muy incipiente y desde el período en que se convoca el Congreso de Panamá y la segunda postguerra (1826-1945) su fundamento es esencialmente ético-legalista, basado en la historia diplomática y los enfoques geopolíticos diseñados por juristas-diplomáticos. Es una política exterior defensiva que se escuda en la normativa ética del Derecho Internacional para resguardar sus fronteras de anexiones y garantizar la supervivencia del estado. Reforzada, esta postura, por los efectos que producen la vecindad geográfica y el peso histórico de sus relaciones con los EEUU.

Pasada esa primera etapa del desarrollo de las Relaciones Internacionales de la región, luego de la segunda postguerra (1945), con las teorías desarrollistas de la CEPAL y los dependentistas (1960-1970), emerge el estructuralismo latinoamericano que enfatiza la dinámica económica del sistema internacional, en la que, se puede afirmar, se empieza a teorizar de forma crítica sobre la política y la economía internacional. Es la primera vez que un grupo de países con escasas capacidades de poder cuestionan el statu quo, desde el punto de vista teórico y práctico, mostrando al mundo una visión de las relaciones entre estados, primordialmente, hasta entonces desconocida, en la que se señalan temas diferentes a los que ocupan la atención de las grandes potencias y en la que se proponen la búsqueda de métodos alternativos que no sólo modifiquen la estructura interna de los estados, sino también la estructura internacional y su dinámica intrínseca.

Una vez desplazado el pensamiento estructuralista por el pensamiento neoliberal (1980) la región optó por reconsiderar los estudios sobre política exterior sobre la base de una hibridación ${ }^{66}$ entre las teorías anglosajonas y la teoría estructuralista-dependentista autóctona, utilizando las categorías de dependencia y autonomía como base del desarrollo de las propuestas teóricas. En este período se asume un análisis desde dos niveles, por un lado, analiza la política internacional y por el otro, formula un modelo de política exterior. Entre los modelos de análisis de política exterior se pueden señalar los de Helio Jaguaribe y su propuesta de autonomía periférica y hegemonía céntrica; Juan Carlos Puig y la autonomía heterodoxa; Lorenzo Meyer y la soberanía relativa; Gerhard Drekonja y la autonomía de bajo y alto perfil; Roberto Russel y Juan Gabriel Tokatlián con la autonomía relacional (ver Anexo Cuadro resumen).

De acuerdo con esto, Roberto Russel y Juan Gabriel Tokatlián ${ }^{67}$ afirman que las

\footnotetext{
${ }^{66}$ Esta hibridación respondía a la necesidad de revertir la constante de épocas anteriores en las que América Latina careció de una política exterior articulada y coherente frente a las distintas crisis interamericanas. También respondía a la recurrencia por parte de los analistas extranjeros de calificar las políticas exteriores de la región como pasivas. Sin embargo, como apunta Gerald Drekonja, los países de la región "aprendieron, acumularon experiencias, desarrollaron sus propios conceptos de política exterior y (...) [entraron] en algunos casos, con decisión y audacia, a la escena internacional" DREKONJA Gerhard, TOKATLIAN, Juan Gabriel. (Eds.), Teoría y práctica de la política exterior latinoamericana, Cerec, CEI, Uniandes, Bogotá 1983, p. 3, citado por VILLARROEL PEÑA, Yetzy, "Modelos de política exterior desde la perspectiva estructuralista latinoamericana en relaciones internacionales", en Revista Politeia, IEP, UCV vol. 39, n 56, Caracas, septiembre, 2016, p. 5.

${ }^{67}$ Estudios recientes de Juan Gabriel Tokatlian y Roberto Russel arrojan que se pudiera pensar en la presencia
} 
diferentes versiones de autonomía derivaron en cuatro opciones estratégicas: 1) equilibrio blando que recurría a las instituciones internacionales, a instrumentos legales, despliegue diplomático y la denuncia, 2) diversificación de lazos externos, 3) el repliegue que consistía en resistencias a asumir compromisos y 4) la unidad colectiva que implicaba aumentar la integración, cooperación y la concertación. Mientras que la dependencia, a la cual denominan, aquiescencia, resulta de la condición de subordinación de la región en el sistema internacional y la pertenencia al área de influencia de Estados Unidos que se consiente implícita o explícitamente ${ }^{68}$.

Es importante señalar que la región latinoamericana está compuesta por 21 estados que dentro de sus grandes coincidencias mantienen sus especificidades nacionales y sociopolíticas, así como de sus propios ritmos internos. En muchos casos las etapas arriba mencionadas pueden aparecer superpuestas, es decir, que el avance de una nueva etapa no significa la desaparición de la anterior.

Otro elemento fundamental de destacar es que a la par que surgen estas propuestas estructuralistas de política exterior, un sustancioso grupo de intelectuales latinoamericanos se inclinan hacia la utilización de la teoría de la interdependencia surgida en el norte anglosajón y se desprecian las propuestas autóctonas, y un amplio grupo se inclina hacia la utilización de la teoría tradicional realista, como por ejemplo Carlos Escudé y su famoso realismo periférico.

Luis Dallanegra Pedraza69 considera que el enfoque que predomina principalmente en la región es la perspectiva política de poder que deriva del realismo político de Morgenthau y Raymond en versión geopolítica y estratégica. Dicho enfoque se basa en la elaboración de hipótesis de conflicto en las que se consideran variables tangibles, como la extensión territorial, número de habitantes, recursos naturales, producción industrial, recursos militares, entre otros, y variables intangibles como el nivel educativo, desarrollo científico, sistema político. Se busca un equilibrio de poder regional desde una visión geopolítica en la que la hipótesis de trabajo plantea la idea de un enemigo externo, generalmente un vecino fronterizo con el que existe alguna disputa territorial o desarrolla una carrera armamentista peligrosa. Además, al enfatizar el realismo el interés nacional y hacerlo en términos de poder para garantizar la seguridad o supervivencia del estado, la política exterior se orienta a buscar ese poder y por eso el uso de visiones de índole geopolítica y estratégica, poco modernas y propias de la antigua tradición de la disciplina.

El resultado del uso de esta perspectiva ha contribuido con la fragmentación distintiva

de una gran estrategia de América Latina si esta se concibe "como un principio orientador de la acción externa de países la región que permanece constante a pesar de los cambios en el 'entorno estratégico' tanto en el plano global como regional" y la región ha contado con dos grandes estrategias en torno a la formulación de sus políticas exteriores por más de cien años, una a la que denominan lógica de autonomía y otra como lógica de aquiescencia. Ambas lógicas han estado presentes en las políticas exteriores de los países de la región e incluso un mismo país ha podido regirse por ambas en distintos momentos de su historia, pero la que ha contado practicada con mayor frecuencia ha sido la de autonomía, "cobra vida a finales del s. XIX, se fortalece en los años de disputa Este-Oeste, pierde importancia relativa en los 90 y resurge con nuevos y viejos contenidos a partir de inicios del s. XXI". RUSSELL, Roberto y TOKATLIAN, Juan Gabriel, "América Latina y su gran estrategia: entre la aquiescencia y la autonomía", Revista CIDOB d'Afers Internacionals, nº 104, Diciembre, 2013, p. 161.

${ }^{68}$ Ibídem.

69 DALLANEGRA PEDRAZA, Luis, Evolución del Debate Técnico-Epistemológico sobre las Relaciones Internacionales, Buenos Aires, 1997. 
de la región desde el siglo XIX, porque hace ver al vecino como enemigo, o en el mejor de los casos, como un peligroso competidor al que hay que restarle poder. Paralelamente, esta perspectiva está acompañada de una concepción jurídica-ética, cosmovisión de lo internacional, que privilegia el Derecho Internacional como código de conducta internacional que se observa en los discursos de los gobiernos y sus respectivas cancillerías, lo que genera una contradicción entre lo que se pregona y lo que se practica. Mientras se exige el cumplimiento del Derecho Internacional se desarrollan concepciones basadas en la perspectiva estratégica de las hipótesis de conflicto.

\section{En guisa de conclusiones}

La historiografía latinoamericana de las relaciones internacionales se caracteriza por mantener en el tiempo factores constantes y por enfrentar situaciones análogas desde el momento en que América Latina entra en contacto con el mundo occidental hasta la actualidad.

Desde el punto de vista ontológico y epistemológico la región se ha debatido entre elaborar un pensamiento propio conforme a su realidad y filosofía específica y pensar conforme a los recursos filosóficos y científicos propios del pensamiento occidental, reproducido generalmente por intelectuales pertenecientes a grupos elitescos vinculados a los círculos de poder, socializados y educados en Europa y los Estados Unidos. Mientras que la formulación de un pensamiento propio original se ha distinguido por ser disidente, crítico, con gran acento social y por mantener una perspectiva interdisciplinaria para explicar los procesos históricos y para producir los cambios deseados en la sociedad, la opción occidentalista se ha caracterizado por justificar y reproducir el statu quo.

Desde el punto de vista conceptual e identitario ha convivido dentro de la historiografía latinoamericana la idea de la excepcionalidad nacional, de la particularidad nacional y su visión excluyente del otro, el vecino, con el vínculo de pertenencia a América Latina, lo cual ha generado avances y retrocesos en cuanto a los procesos de integración y unificación regional, ante la incompatibilidad de ambas visiones. En ese sentido la historiografía que se ha privilegiado ha sido la nacional, la cual contribuye a reproducir la idea de excepcionalidad nacional y sus problemáticas, mientras se ha dejado de lado los temas comunes a todos los países de la región. Esto a su vez ha alimentado ambiciones y rivalidades entre vecinos.

Paradójicamente, es fuera de la región en dónde proliferan las primeras investigaciones en las que el objeto de estudio es América Latina de forma global. Aunque posteriormente, con el avance de las ciencias sociales latinoamericanas, grupos importantes de intelectuales latinoamericanos se constituyeron en torno a grupos de investigación cada vez más importantes y sólidos como Consejo Latinoamericano de Ciencias Sociales (CLACSO), la Facultad Latinoamericana de Ciencias Social (FLACSO), entre muchos otros.

Desde el punto de vista práctico la región siempre ha estado subordinada a una potencia dominante, sea colonial o neocolonial, que establece las reglas de comportamiento internacional y hace pagar caro las insubordinaciones, que además cuenta con el apoyo interno de grupos tradicionalmente dominantes y con otros estados de la región. En contrapartida este comportamiento internacional ha generado voces disidentes, autonomistas que reivindican valores diferentes a los hegemónicos occidentales y que a su vez cuentan con el apoyo de 
sectores populares y puede incluso contar con anuencia de otros estados de la región. En síntesis esta situación revela una recurrente dependencia de diversas índoles de Latinoamérica de la potencia de turno.

De igual manera ha sido recurrente que estos grupos disidentes al ser acorralados o aislados por acciones de la potencia dominante, acuden a buscar la ayuda de otras potencias adversarias o buscan constituir bloques con países que sean afectos a la idea de modificar el statu quo, basándose en concepciones de unidad, solidaridad, cooperación, entre otras. Es interesante, igualmente, constatar que generalmente cuando se han producido voces disidentes, estas emergen estratégicamente favorecidas por la coyuntura internacional y nacional. Por ejemplo, una crisis de la metrópolis, crisis del capitalismo, una guerra internacional (I y II Guerra Mundial) junto con condiciones internas que permitan el ascenso al poder de actores no tradicionales o de ascendencia popular. No obstante, una vez que se produce el equilibrio internacional es recurrente que los avances alcanzados en términos de autonomía sean revertidos.

El siglo XXI con su avalancha de hechos que sobrepasan las teorías y las capacidades para entender los cambios que los mismos producen, hace cada vez más imprescindible el uso, la reflexión y la revisión de la historia para entender el presente y las nuevas situaciones, lo cual permita entender dónde nos ubicamos como región y qué acciones pueden ser las mejores opciones de los países de la región en términos de autonomía, sociales, políticos, económicos, ecológicos, humanos. Pero a su vez, también es necesario dirigir la reflexión hacia cómo se ha utilizado la historiografía y cuál es el uso que se debe dar en el presente, preguntándonos ¿realmente hemos entendido la historia de manera correcta? ¿Hay posibilidades de nuevas formas de pensar la historia? ¿Está permitido pensar en términos diferentes la historia? y si no lo está ¿qué hacer desde los espacios académicos para lograr que sea posible? Hoy más que nunca la región requiere de estudiosos de la historia latinoamericana en relaciones internacionales, porque muchos de los dilemas que ocuparon a los fundadores de la región siguen vigentes, no resueltos, o no resueltos del todo, porque por ejemplo, el tema de cómo alcanzar una mejor inserción internacional sigue siendo un asunto importante por resolver, y aunque se han hecho aportes valiosos desde el punto de vista teórico, e incluso práctico, estos no han sido suficientes y requieren de una permanente revisión y reflexión crítica.

\section{Bibliografía}

ACOSTA, Yamandú et. al., América Latina piensa América Latina, CLACSO, Buenos Aires, 2015.

ANSALDI, Waldo, "Entre perplejidades y angustias. Vota para pensar las Ciencias Sociales Latinoamericanas", Revista de Estudos \& Pesquisas sobre as Américas, vol. 8, n² 2, 2014, ps. 15-38.

ARDAO, Arturo, Nuestra América Latina, Ediciones de la Banda Oriental, Temas Latinoamericanos, Montevideo, 1986.

AROSTEGUI, Julio, A investigación histórica. Teoría y Método, Editorial crítica, Barcelona, 1995.

BERNAL MEZA, Raúl, América Latina en el mundo. El pensamiento latinoamericano y la teoría de las relaciones internacionales, Nuevo hacer Grupo Editor Latinoamericano, Buenos Aires, 2005.

BOBBio, Norberto, Diccionario de Política, Siglo XXI Editores, Tomo II, Madrid, 2000. 12a Edición, [1era. Ed. en Español1981-1982].

BOERSNER, Demetrio, Relaciones Internacionales de América Latina. Breve Historia, Editorial Nueva Sociedad, Caracas, 1990, [1era. Ed. 1982].

BRITO FIGUEROA, Federico, Historia económica y social de Venezuela, Ediciones de la UCV, Caracas, 1972. 
CARRERA DAMAS, Germán, Una nación llamada Venezuela, 5ta. ed., Monte Ávila Editores Latinoamericanos, Caracas, 1997.

CERVO, Amado Luiz, Relações internacionais da América Latina: velhos e novos paradigmas, Saraiva, São Paulo, 2007.

COMISIÓN ECONOMICA PARA AMÉRICA LATINA, La Transformación Productiva 20 Años Después: Viejos Problemas, Nuevas Oportunidades, CEPAL/ONU, Santiago de Chile, mayo, 2008.

CHIARAMONTE, Carlos, Pensamiento de la Ilustración. Economía y Sociedad Iberoamericana en el siglo XVII, $2^{a}$ ed., Biblioteca Ayacucho, Caracas, 1992.

CHOQUEHUANCA, David, Secretario Ejecutivo del ALBA ATP, Caracas, 10/08/2017 en DOSSIER, Venezolana de Televisión, cadena de televisión pública de Venezuela:https://www.youtube. $\mathrm{com} /$ watch?v=FUf48UiOanQ\&list=PLAuUAmNdy82U5DGqqjelwM1wX4QTdU6Ow [Consultado $10 / 08 / 2017]$

DALLANEGRA PEDRAZA, Luis, Evolución del Debate Técnico-Epistemológico sobre las Relaciones Internacionales, Buenos Aires, 1997.

DREKONJA Gerhard, TOKATLIAN, Juan Gabriel, (Ed.) Teoría y Práctica de la Política Exterior Latinoamericana, CEREC/ CEI/ UNIANDES, Bogotá, 1983.

DEVÉS, Eduardo, El Pensamiento Latinoamericano en el Siglo XX. Entre la Modernidad y la Identidad. Del Ariel de Rodó a la CEPAL, Tomo I, Editorial Biblos, Centro de Investigaciones Diego Barros Arana, Buenos Aires, 2000.

DEVÉS, Eduardo, El Pensamiento Latinoamericano en el Siglo XX. Entre la Modernidad y la Identidad. Desde la CEPAL al neoliberalismo (1950-1990), Tomo II, Editorial Biblos/ Centro de Investigaciones Diego Barros Arana, Buenos Aires, 2003.

DEVÉS, Eduardo, El Pensamiento Latinoamericano en el Siglo XX. Entre la Modernidad y la Identidad. Las Discusiones y las Figuras del Fin de Siglo. Los Años 90, Tomo III, Editorial Biblos/ Centro de Investigaciones Diego Barros Arana, Buenos Aires, 2004.

ESCANDÓN, Patricia, "Cartas, Diarios y Memoriales del periodo colonial como material historiográfico", Anuario de Estudios Latinoamericanos, Universidad Autónoma de México, n 3, México, 2002.

ESCUDÉ, Carlos, "La política exterior de Menem y su sustento teórico implícito", América Latina/Internacional, vol. 8, no 27, enero-marzo, 1991, ps. 394-406,

ESCUDÉ, Carlos, Realismo Periférico: Fundamentos para la Nueva Política Exterior Argentina, Editorial Planeta, Buenos Aires 1992.

GAOS, José, "Notas sobre la historiografía" en Historias. Boletín de Información de Investigaciones Históricas, UNAM, N 6, mayo-agosto, 1981.

GUERRA, Cristina, "Modelos Epistemológicos y metodológicos en el desarrollo de la historia". Disponible en http://www.didacticadelahistoria.unlu.edu.ar/sites/www.didacticadelahistoria.unlu.edu.ar/ files/site/MODELOS\%20EPISTEMOL\%C3\%93GICOS\%20Y\%20METODOL\%C3\%93GICOS\%20 EN\%20EL\%20DESARROLLO\%20DE\%20LA\%20HISTORIA.pdf

HANKEL, Lewis, "¿Tienen las Américas una Historia común? Crítica a la teoría de H.E. Bolton", Anuario, Facultad de Humanidades y Educación, Tomo I, Caracas, 1964.

HERRERA, Edmundo, Relaciones Internacionales. I. Gestación y nacimiento, Nuevo Hacer Grupo Editorial Latinoamericano, Buenos Aires, 2006.

HEREDIA, Edmundo, "Relaciones Internacionales Latinoamericanas: historiografía y teorías" en Estudios Iberoamericanos, PUCRS, v. XXXIV, n 1, 2008, ps. 7-35.

HOBSBAWM, Erick, Nacionalismo y Naciones desde 1780, Trad. Jordi Beltrán, Editorial Crítica, Barcelona, 1991.

HOLSTI, Kalevi Jaakko, The Dividing Discipline: Hegemony and Diversity in International Theory, Houghton Mifflin, Boston, 1985.

IWASAKI, Fernando, "Del Estado nación al estado de la nación. Una mirada historiográfica", Conferencia dictada en Casa América con motivo de la celebración de sus 25 años, 27 de abril de 2017 en https://www.youtube.com/watch?v=_hClanwq1BY [Consultado: 15 noviembre 2017]

LEAL, Ildefonso, Nuevas Crónicas de Historia de Venezuela, Academia Nacional de la Historia, Tomo I, no 37, Caracas, 1985.

JAGUARIBE, "Helio Hegemonía céntrica y autonomía periférica", en HILL, E. y TOMASSINi, L. (Comps.) América Latina y el nuevo orden económico internacional, Editorial Belgrano, Buenos Aires, 1982, pp. 17-48.

LECHNER, Norbert, Obras Escogidas, Colección Pensadores Latinoamericanos, LOM Ediciones, Chile, 2006.

LEPKOWSKI, Tadeusz, "Formación de nacionalidades en América Latina (1780-1830). Reflexiones generales y algunos casos específicos", en Congreso Bicentenario de Simón Bolívar, Academia Nacional de la Historia, tomo III, Caracas, 1983.

MARTINIĖRE, Guy, Les Amérique latines, Presses de I'Université de Grenoble, Grenoble, 1978.

MARTINIĖRE, Guy, "La Escuela de los «Annales» y las Américas Latinas (1929 -1949)", Estudios Latinoamericanos, vol. 6, 1980, ps. 133-153. 
MEYER, Lorenzo, "Cambio político y dependencia, México en el siglo XX", Foro Internacional, vol. XIII, $\mathrm{n}^{\circ} 2$, octubre-diciembre, 1972.

MEYER, Lorenzo, "México-EE.UU.: las etapas de una relación difícil", SECRETARÍA DE RELACIONES EXTERIORES, Política exterior de México, 175 años de historia, México, 1985, ps. 132-147.

MEYER, Lorenzo, "México y la soberanía relativa. El vaivén de los alcances y los límites", Foro Internacional, vol. XLVIII, n 4, 2008, pp. 765-784.

PERINA, Rubén, "Estudios de las Relaciones Internacionales en Universidades de América Latina y el Caribe", en Integración de Latinoamericana, no 81, año 8, 1983, ps.38-44.

PICÓN SALAS, Mariano, Dependencia e independencia en la historia hispanoamericana, Ediciones Cruz del Sur, Caracas, 1952.

POMBO, Rocha, Compendio de Historia de Americana, Laenment e Co., Río de Janeiro, 1900.

PUIG, Juan Carlos, Doctrinas internacionales y autonomía latinoamericana, Instituto de Altos Estudios de América Latina, Universidad Simón Bolívar, Caracas, 1980.

PRIMER CONGRESO DEL PENSAMIENTO POLÍTICO LATINOAMERICANO, Ediciones del Bicentenario del Natalicio del Libertador Simón Bolívar/ Congreso de la República de Venezuela, Tomo II, Vol. I, Caracas, 1983.

RAPOPORT, Mario, CERVO, Amado Luiz, (Comp) Historia del Cono Sur, Editorial Revan, Río de Janeiro, 1998.

RAPOPORT, Mario, "Una contribución al estudio de la historia de las relaciones internacionales en América Latina desde fines del siglo XX" http://www.mariorapoport.com.ar/uploadsarchivos/ horizontes_latinoamericanos.pdf [Consultado: 15 noviembre 2017]

REUS-SMITH, Cristian, "Leyendo la historia con una mirada constructivista", Revista Relaciones Internacionales, GERI, UAM, n²0, junio, 2012, ps. 63-83.

RIVAS, Ricardo, "El origen de la nación y los historiadores latinoamericanos", Cuadernos de CISH, vo 1 , $\mathrm{n}^{\circ} 1$, Universidad de la Plata, 1996, ps. 52-61.

RUSSELL, Roberto. (Ed.) Enfoques Teóricos para el Estudio de la Política Exterior, RIAL-GEL, Buenos Aires, 1992.

RUSSELL, Roberto, TOKATLIAN, Juan Gabriel, "De la autonomía antagónica a la autonomía relacional: una mirada teórica desde el Cono Sur", Perfiles Latinoamericanos, n 21, diciembre, 2002, ps. 159-194.

RUSSELL, Roberto y TOKATLIAN, Juan Gabriel, "América Latina y su gran estrategia: entre la aquiescencia y la autonomía", Revista CIDOB d'Afers Internacionals, n 104, Diciembre, 2013, ps. 157-180.

SALAS ASTRIAN, Ricardo (Coord.), Pensamiento Político Latinoamericano. Conceptos Fundamentales, Ediciones de la Universidad Católica Silva Henríquez, Santiago de Chile, vol. II, 2005.

SAVATER, Fernando, Política para Amador, Editorial Ariel S. A., Barcelona, 1997.

SIMONOFF, Alejandro, Los Dilemas de la Autonomía: La Política Exterior de Arturo Illia (1963-1966), Grupo Editor Latinoamericano, Buenos Aires, 2007.

SOLER, Ricaurte, Ideas de la cuestión nacional latinoamericanas de la emergencia del imperialismo, México, 1980.

SORIANO DE GARCÍA PELAYO, Graciela, "El sentido de la Historia en dos siglos" en Visiones del siglo XX venezolano, Comisión Presidencial V Centenario de Venezuela/CELARG, Caracas, 8 al 12 de noviembre 1999.

SUNKEL Oswaldo, "Raúl Prebisch y los desafíos del desarrollo del siglo XXI", CEPAL, 23 de marzo 2013. Disponible en: https://www.youtube.com/watch?v=qGrsBqIaoD0

TICKNER, Arlene, "Latin American IR and the Primacy of lo práctico" en International Studies Review, vol 10, Issue 4, December, 2008, ps. 735-748.

TICKNER, Arlene, Los Estudios Internacionales en América Latina ¿Subordinación Intelectual o Pensamiento Emancipatorio?, Alfaomega Editores, Bogotá, 2002.

TOMASSINI, Luciano, "El Proceso de Globalización y América Latina" en Integración Solidaria: Reconstrucción de los sistemas políticos Latinoamericanos. II, Caracas, USB/IAEAL, 1993, ps. 294-295.

VILLARROEL PEÑA, Yetzy, Naturaleza y Perspectivas de los nacionalismos frente a la globalización. Consecuencias Políticas, Tesis de Maestría, Universidad Simón Bolívar, 2004.

VILLARROEL PEÑA, Yetzy, Vigencia teórica de la perspectiva estructural dependentista latinoamericana de las Relaciones Internacionales, Tesis Doctoral, Universidad Simón Bolívar, 2011.

VILLARROEL PEÑA, Yetzy, América Latina y su papel en la configuración del Derecho Internacional", Revista Politeia, IEP, UCV, vol. 34, n 46, Caracas, junio, 2011, ps. 111-131.

VILLARROEL PEÑA, Yetzy, "Modelos de Política Exterior desde la Perspectiva Estructuralista Latinoamericana en Relaciones Internacionales" en Revista Politeia, IEP, UCV vol. 39, n 56, Caracas, septiembre, 2016.

ZEA, Leopoldo (Comp.), Pensamiento Positivista Latinoamericano, Biblioteca Ayacucho, Tomo I y II, nº 71-72, Caracas, 1980. 


\begin{tabular}{|c|c|c|c|}
\hline \multicolumn{4}{|c|}{ Resemantización de la variable Autonomía en los estudios latinoamericanos } \\
\hline Época & $\begin{array}{c}\text { Corriente de } \\
\text { pensamiento/Autores }\end{array}$ & Significado de Autonomía & Propuesta \\
\hline $\begin{array}{c}\text { Siglo XIX } \\
\mathbf{y} \mathbf{X X} \\
1810-1830\end{array}$ & $\begin{array}{l}\text { Movimiento Político } \\
\text { Próceres de la } \\
\text { Independencia } \\
\text { Latinoamericana }\end{array}$ & $\begin{array}{l}\text { Emancipación o } \\
\text { independencia política. } \\
\text { Cualidad jurídica de los } \\
\text { Estados para actuar } \\
\text { libremente. }\end{array}$ & $\begin{array}{l}\text { Conformación de Estados } \\
\text { nacionales, Nacionalismos } \\
\text { Políticos. Muerte del } \\
\text { Regionalismo. }\end{array}$ \\
\hline $\begin{array}{l}\text { Siglo XIX } \\
\mathbf{y} \mathbf{X X} \\
1830- \\
1920\end{array}$ & $\begin{array}{l}\text { Movimiento } \\
\text { culturalista } \\
\text { Andrés Bello, Manuel } \\
\text { Ugarte, Esteban } \\
\text { Echeverría, Juan Bautista } \\
\text { Alberdi, José Ingenieros, } \\
\text { Eugenio María de Hostos. }\end{array}$ & $\begin{array}{l}\text { Emancipación cultural } \\
\text { (de la mente) o segunda } \\
\text { independencia. Cualidad de } \\
\text { la población de un Estado de } \\
\text { vivir conforme a su cultura } \\
\text { y produciendo sus propias } \\
\text { teorías y categorías de } \\
\text { análisis. }\end{array}$ & $\begin{array}{l}\text { La emancipación está } \\
\text { incompleta, queda } \\
\text { pendiente la emancipación } \\
\text { económica, social y cultural } \\
\text { como complemento. Debate } \\
\text { entre cosmopolitismo y } \\
\text { nacionalismo, así como } \\
\text { propuestas teóricas en las } \\
\text { que se articula la lucha } \\
\text { contra el Imperialismo. } \\
\text { Nacionalismo Cultural y } \\
\text { Soberanía estatal. }\end{array}$ \\
\hline \multirow[t]{2}{*}{$\begin{array}{l}\text { Siglo XX } \\
1930-1970\end{array}$} & $\begin{array}{l}\text { Estructuralismo: Críticos } \\
\text { de la modernización } \\
\text { económica. } \\
\text { José Carlos Mariátegui, } \\
\text { Gilberto Freire, Raúl } \\
\text { Prebisch. }\end{array}$ & $\begin{array}{l}\text { Emancipación económica } \\
\text { entendida como } \\
\text { autosuficiencia económica. }\end{array}$ & $\begin{array}{l}\text { Alcanzar el desarrollo } \\
\text { económico por medio de } \\
\text { la industrialización y la } \\
\text { integración latinoamericana. }\end{array}$ \\
\hline & $\begin{array}{l}\text { Estructuralismo: } \\
\text { Dependentistas Dos } \\
\text { Santos, Quijano, Sunkel, } \\
\text { Cardoso, Furtado, } \\
\text { Falletto, Marini, Gunder } \\
\text { Frank. }\end{array}$ & $\begin{array}{l}\text { Sólo el centro es autónomo, } \\
\text { la periferia es dependiente } \\
\text { con sectores internos } \\
\text { subordinados. }\end{array}$ & $\begin{array}{l}\text { Disolver las causas } \\
\text { estructurales del } \\
\text { subdesarrollo. Los más } \\
\text { radicales proponían la } \\
\text { ruptura radical con el } \\
\text { capitalismo para adoptar } \\
\text { una forma alternativa de } \\
\text { desarrollo. }\end{array}$ \\
\hline $\begin{array}{l}\underset{\mathbf{X X I}}{\text { Siglo XX } \mathbf{y}} \\
1980-2000\end{array}$ & $\begin{array}{l}\text { Post-estructuralismo: } \\
\text { Análisis de Política } \\
\text { Exterior }\end{array}$ & $\begin{array}{l}\text { La autonomía como objetivo } \\
\text { de Política Exterior. }\end{array}$ & $\begin{array}{l}\text { Formulación de Políticas } \\
\text { exteriores más dinámicas } \\
\text { y activas que busquen } \\
\text { alcanzar mayores niveles de } \\
\text { autonomía. }\end{array}$ \\
\hline
\end{tabular}

Fuente: Elaboración propia basado en la lectura de varias fuentes 


\begin{tabular}{|c|c|c|c|}
\hline \multicolumn{4}{|c|}{ Resemantización de la variable Autonomía en Política Exterior } \\
\hline Época & $\begin{array}{c}\text { Corriente de } \\
\text { pensamiento/Autores }\end{array}$ & Significado de Autonomía & Propuesta \\
\hline $\begin{array}{c}\begin{array}{c}\text { Guerra } \\
\text { Fría }\end{array} \\
1970\end{array}$ & $\begin{array}{l}\text { Helio Jaguaribe: } \\
\text { Autonomía Periférica y } \\
\text { Hegemonía Céntrica }\end{array}$ & $\begin{array}{l}\text { Objetivo de Política Exterior. } \\
\text { Es cualidad o capacidad para } \\
\text { "disponer de medios para } \\
\text { imponer severas penalidades, } \\
\text { materiales y morales, a un } \\
\text { eventual agresor". (1982; } \\
\text { 19) }\end{array}$ & $\begin{array}{l}\text { Política exterior activa y de } \\
\text { alto perfil. } \\
\text { Se debe plantear una } \\
\text { optimización de los } \\
\text { principales intereses del } \\
\text { Estado, considerando la } \\
\text { viabilidad de acción que } \\
\text { permiten sus recursos } \\
\text { internos y la permisibilidad } \\
\text { del sistema internacional } \\
\text { que lo haga favorable. }\end{array}$ \\
\hline $\begin{array}{l}\text { Guerra } \\
\text { Fría } \\
1980\end{array}$ & $\begin{array}{l}\text { Juan Carlos Puig: } \\
\text { Autonomía Heterodoxa }\end{array}$ & $\begin{array}{l}\text { También tiene un contenido } \\
\text { político en el que la } \\
\text { autonomía es una capacidad } \\
\text { del Estado y un objetivo } \\
\text { de Política Exterior. Es } \\
\text { "la máxima capacidad de } \\
\text { decisión propia que se puede } \\
\text { tener, teniendo en cuenta los } \\
\text { condicionamiento objetivos } \\
\text { del mundo real"(1980; 149) }\end{array}$ & $\begin{array}{l}\text { Aumentar de manera } \\
\text { progresiva las condiciones } \\
\text { de viabilidad nacional, } \\
\text { aceptando la existencia } \\
\text { de un poder hegemónico } \\
\text { pero se disiente con éste } \\
\text { y se deslinda el interés } \\
\text { nacional del Estado del de } \\
\text { la potencia hegemónica. } \\
\text { Tras la superación de un } \\
\text { estadio de dependencia se } \\
\text { gana autonomía sin generar } \\
\text { condiciones extremas de } \\
\text { sumisión o de ruptura con } \\
\text { la potencia a través del } \\
\text { desarrollo de estrategias de } \\
\text { autonomía. }\end{array}$ \\
\hline
\end{tabular}

Fuente: Elaboración propia basado en la lectura de varias fuentes 


\begin{tabular}{|c|c|c|c|}
\hline \multicolumn{4}{|c|}{ Resemantización de la variable Autonomía en Política Exterior } \\
\hline Época & $\begin{array}{c}\text { Corriente de } \\
\text { pensamiento/Autores }\end{array}$ & $\begin{array}{c}\text { Significado de } \\
\text { Autonomía }\end{array}$ & Propuesta \\
\hline $\begin{array}{l}\text { Guerra Fría } \\
1985 \\
\text { Postguerra } \\
\text { Fría } \\
2008\end{array}$ & $\begin{array}{l}\text { Lorenzo Meyer: } \\
\text { soberanía } \\
\text { dependiente o } \\
\text { soberanía relativa }\end{array}$ & $\begin{array}{l}\text { La política exterior de } \\
\text { México debe considerar } \\
\text { dos aspectos que } \\
\text { siempre han influido } \\
\text { directamente en su } \\
\text { actuación internacional, } \\
\text { 1) la cercanía geográfico- } \\
\text { fronteriza con Estados } \\
\text { Unidos, 2) el peso } \\
\text { histórico de la relaciones } \\
\text { entre ambos países. } \\
\text { Ambas variables, } \\
\text { a su vez, estarían } \\
\text { determinadas a lo largo } \\
\text { del tiempo "por el hecho } \\
\text { de la desigualdad inicial } \\
\text { y creciente en el poderío } \\
\text { de los dos países" (Meyer, } \\
\text { 1985) } \\
\text { México más que nunca } \\
\text { aparece como un satélite } \\
\text { de Estados Unidos, } \\
\text { lo que condiciona la } \\
\text { soberanía e independencia } \\
\text { nacional mexicana, } \\
\text { "una independencia } \\
\text { trabajosamente negociada } \\
\text { con nuestro vecino del } \\
\text { Norte". }\end{array}$ & $\begin{array}{l}\text { Muestra las etapas de la } \\
\text { naturaleza de las relaciones } \\
\text { exteriores de México y } \\
\text { Estados Unidos: 1) Siglo } \\
\text { XIX, desde la independencia, } \\
\text { de expansión territorial. 2) } \\
\text { Siglo XX, de dominación } \\
\text { económica. 3) Entre } 1910 \text { y } \\
\text { la II GM, como un momento } \\
\text { de acuerdo y callejones sin } \\
\text { salida. 4) Después de la } \\
\text { II GM, de coincidencias de } \\
\text { intereses, alianza formal } \\
\text { contra las potencias del eje. } \\
\text { 5) Después de } 1946, \text { de } \\
\text { distanciamiento de Estados } \\
\text { Unidos y prudencia de } \\
\text { México. 6) Entre 1964-1970, } \\
\text { la mirada de México gira } \\
\text { hacia Centroamérica para } \\
\text { competir con Estados Unidos } \\
\text { de manera modesta. 7) Entre } \\
\text { 1973-1982, de marcada } \\
\text { dependencia externa, se } \\
\text { acerca al Tercer Mundo, } \\
\text { aunque la crisis energética } \\
\text { le dio a México nuevas } \\
\text { capacidades de poder (p. } \\
\text { 139). En la década de los } \\
\text { noventa del siglo XX, de la } \\
\text { crisis de la deuda al Tratado } \\
\text { de Libre Comercio se redujo } \\
\text { considerablemente el espacio } \\
\text { de maniobra internacional } \\
\text { (Meyer, 2008). }\end{array}$ \\
\hline
\end{tabular}

Fuente: Elaboración propia basado en la lectura de varias fuentes 


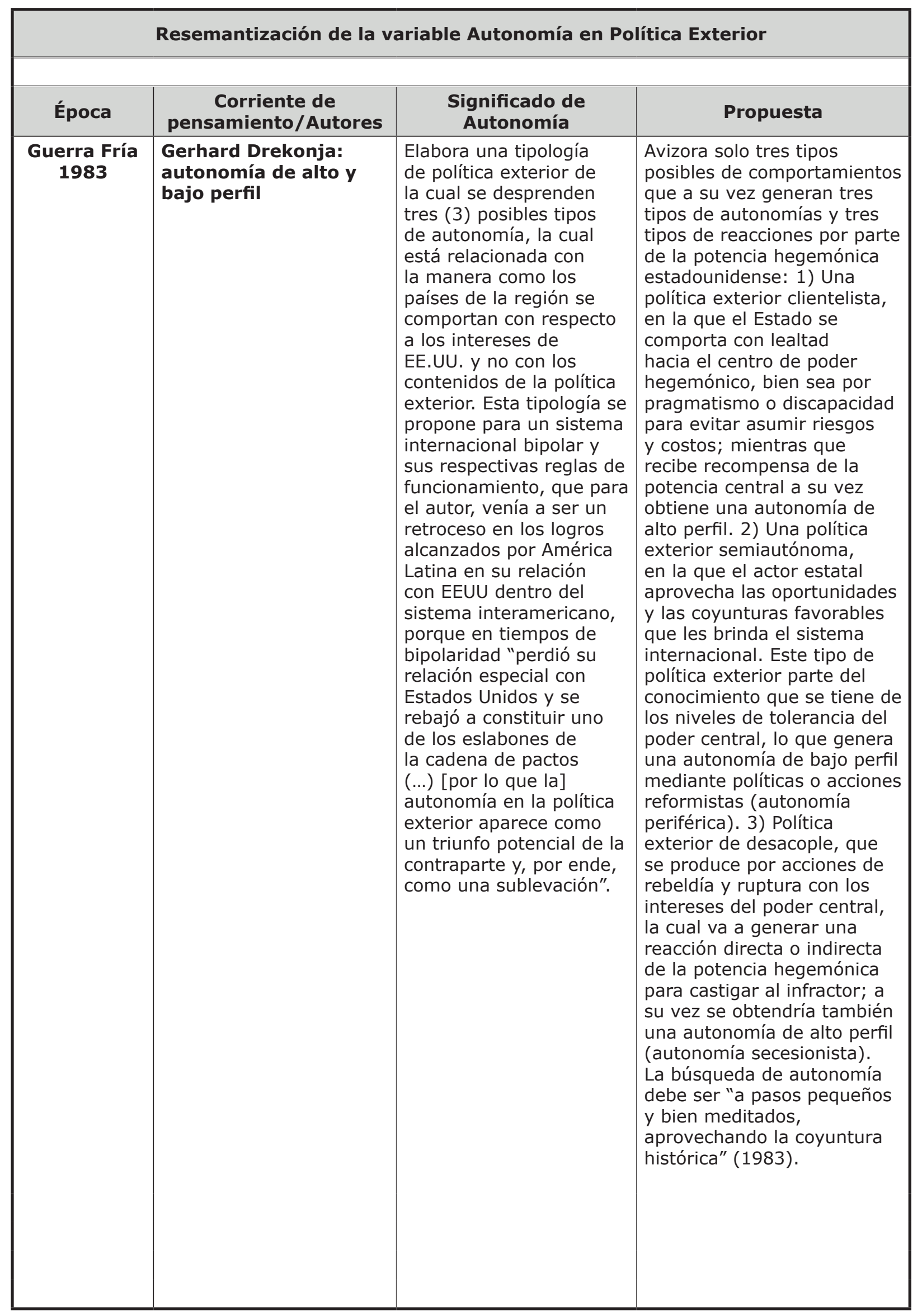

Fuente: Elaboración propia basado en la lectura de varias fuentes 


\begin{tabular}{|c|c|c|c|}
\hline \multicolumn{4}{|c|}{ Resemantización de la variable Autonomía en Política Exterior } \\
\hline Época & $\begin{array}{c}\text { Corriente de } \\
\text { pensamiento/Autores }\end{array}$ & $\begin{array}{l}\text { Significado de } \\
\text { Autonomía }\end{array}$ & Propuesta \\
\hline $\begin{array}{l}\text { Postguerra } \\
\text { Fría } \\
1990\end{array}$ & $\begin{array}{l}\text { Carlos Escudé: } \\
\text { Realismo Periférico }\end{array}$ & $\begin{array}{l}\text { Todo Estado por el hecho } \\
\text { de ser Estado goza de } \\
\text { autonomía, pero ésta } \\
\text { cuando se utiliza de } \\
\text { forma desmedida puede } \\
\text { ser auto-destructiva. La } \\
\text { política exterior debe } \\
\text { considerar "un riguroso } \\
\text { cálculo de costos y } \\
\text { beneficios materiales, } \\
\text { sino también en función } \\
\text { de los riesgos de costos } \\
\text { eventuales" (1991; 396). } \\
\text { La autonomía es un } \\
\text { riesgo, no un objetivo de } \\
\text { política exterior. }\end{array}$ & $\begin{array}{l}\text { La Política Exterior debe } \\
\text { orientarse hacia acciones } \\
\text { que eviten confrontaciones } \\
\text { que desafíen a la potencia } \\
\text { hegemónica. El objetivo } \\
\text { fundamental de ésta no } \\
\text { es buscar autonomía, sino } \\
\text { buscar bienestar el de la } \\
\text { gente, el comercio, las } \\
\text { finanzas. }\end{array}$ \\
\hline $\begin{array}{l}\text { Siglo XXI } \\
\text { Postguerra } \\
\text { Fría } \\
2000\end{array}$ & $\begin{array}{l}\text { Juan Gabriel Tokatlian } \\
\text { y Roberto Russell: } \\
\text { Autonomía Relacional }\end{array}$ & $\begin{array}{l}\text { La autonomía es "la } \\
\text { capacidad del país de } \\
\text { tomar decisiones con } \\
\text { otros por voluntad propia } \\
\text { y para hacer frente } \\
\text { en forma conjunta a } \\
\text { situaciones y procesos } \\
\text { ocurridos dentro y fuera } \\
\text { de sus fronteras"(2002; } \\
176)\end{array}$ & $\begin{array}{l}\text { El ejercicio de la autonomía } \\
\text { relacional está diseñado } \\
\text { para América del Sur, la } \\
\text { misma no se evaluaría en } \\
\text { función de su oposición } \\
\text { hacia los Estados Unidos, } \\
\text { sino a la capacidad } \\
\text { propia de establecer y } \\
\text { ejecutar políticas que más } \\
\text { contribuyan al interés } \\
\text { nacional. Se procura } \\
\text { mediante una estrategia } \\
\text { de regionalización o } \\
\text { internacionalización. } \\
\text { Favorecer el compromiso, } \\
\text { la negociación, fuerte } \\
\text { participación e influjo de } \\
\text { las sociedades nacionales. } \\
\text { Profundizar vínculos } \\
\text { comerciales, financieros y de } \\
\text { inversión. }\end{array}$ \\
\hline
\end{tabular}

Fuente: Elaboración propia basado en la lectura de varias fuentes 


\section{RELACIONES INTERNACIONALES}

Revista académica cuatrimestral de publicación electrónica Grupo de Estudios de Relaciones Internacionales (GERI) Universidad Autónoma de Madrid, España

www.relacionesinternacionales.info

ISSN 1699 - 3950

ff facebook.com/RelacionesInternacionales

twitter.com/RRInternacional 